\title{
Colored Janus Nanocylinders Driven by \\ Supramolecular Co-Assembly of Donor and \\ Acceptor Building Blocks
}

by Thomas Choisnet, David Canevet, Marc Sallé, Cédric Lorthioir, Laurent Bouteiller, Patrice

Woisel, Frédérick Niepceron, Erwan Nicol, Olivier Colombani

1. Synthesis of the polymers

PEO-NDI- $\mathrm{U}_{2}$ was synthesized according to a procedure previously described ${ }^{1}$.

DAN- $U_{2}-$ PHEA was synthesized according to the route described in scheme $\mathrm{S} 1$. The experimental details are given hereafter. 

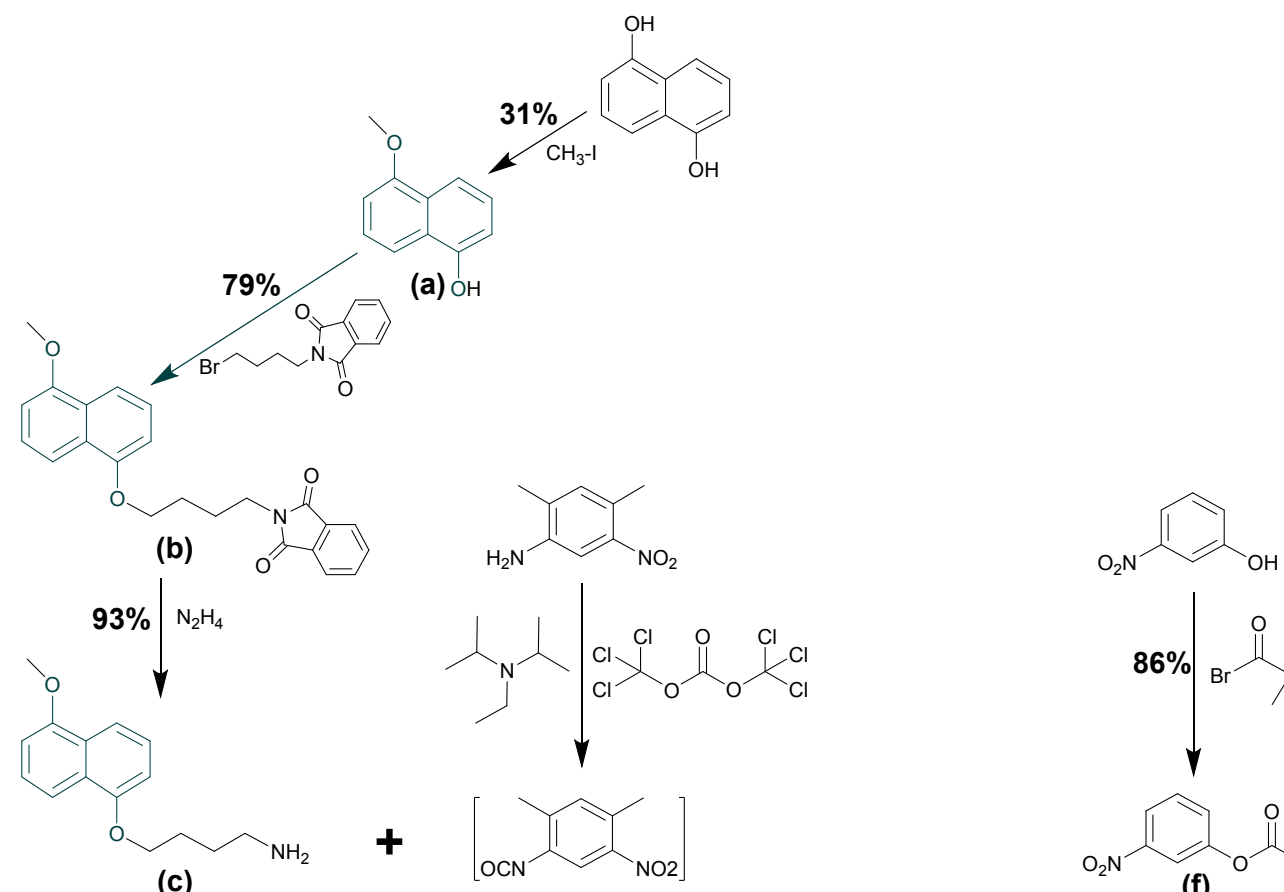

(c)
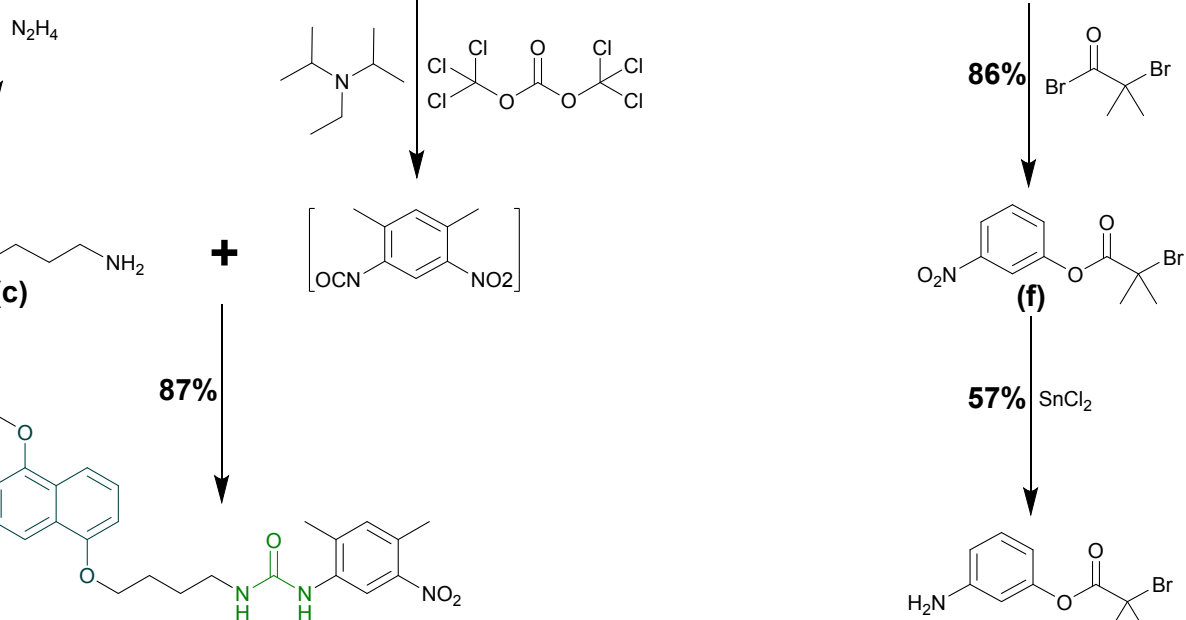

(d)

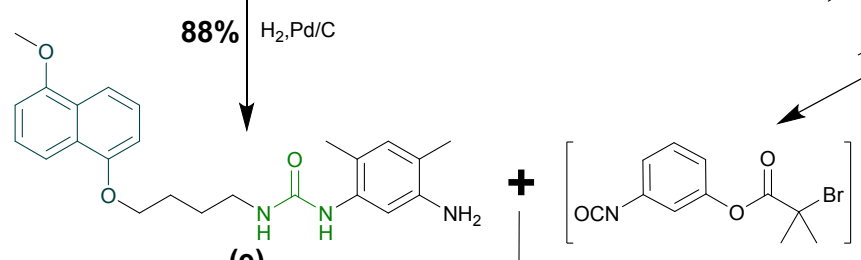

(e)

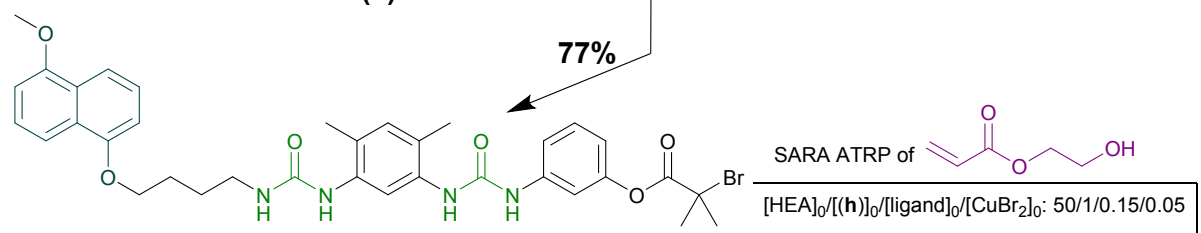

(h)

overall yield $=7 \%$

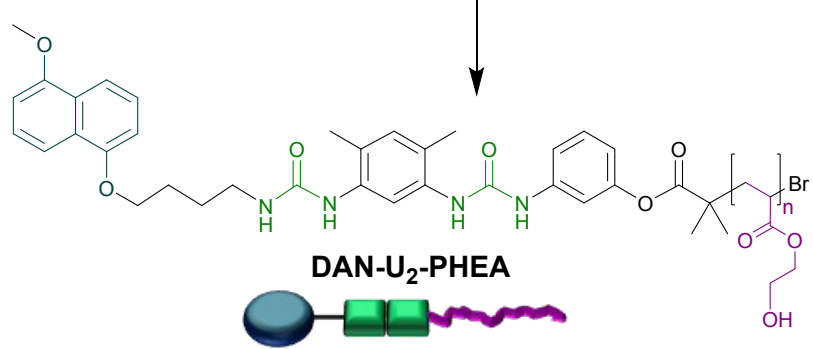


Scheme $\mathrm{S} 1$. Synthesis route of DAN-U $\mathrm{U}_{2}-\mathrm{PHEA}$

\section{5-methoxynaphthalen-1-ol (a):}

5-Methoxynaphthalen-1-ol was synthesized according to a procedure derived from Iverson et al. ${ }^{9}$. In a $50 \mathrm{~mL}$ three-necked round bottom flask equipped with a stirring bar and a condenser, 1,5-dihydroxynaphthalene $(1.00 \mathrm{~g}, 6.3 \mathrm{mmol}, 1 \mathrm{eq}$.$) and potassium$ carbonate $(0.95 \mathrm{~g}, 6.9 \mathrm{mmol}, 1.1 \mathrm{eq}$.) were dissolved in acetonitrile $(40 \mathrm{~mL})$. The flask was purged with argon before the dropwise addition of iodomethane $(0.4 \mathrm{~mL}, 6.4 \mathrm{mmol}$, 1 eq.). The reaction mixture was stirred overnight under reflux. After cooling down to room temperature, acetonitrile was removed under vacuum and the resulting black mixture was dissolved in dichloromethane and filtered through dicalite. The filtrate was washed three times with a saturated solution of sodium hydrogen carbonate, followed by three times washing with brine and dried over magnesium sulfate. The solution was concentrated and the crude product was purified on a silica gel chromatography using an $8 / 2$ mixture of dichloromethane and petroleum ether as eluent to afford a crystalline yellow solid (0.345 g, $1.98 \mathrm{mmol}, 31 \%$ yield). 
${ }^{1} \mathrm{H}$ NMR $\left(300 \mathrm{MHz}, \mathrm{CDCl}_{3}\right)$, Figure S1, $\delta(\mathrm{ppm})=7.85\left(\mathrm{~d}, \mathrm{~J}=8.5 \mathrm{~Hz}, \mathrm{H}_{\mathrm{d}}\right), 7.74(\mathrm{~d}, \mathrm{~J}=$ $\left.8.5 \mathrm{~Hz}, \mathrm{H}_{\mathrm{e}}\right), 7.40\left(\mathrm{t}, \mathrm{J}=8.0 \mathrm{~Hz}, \mathrm{H}_{\mathrm{c}}\right), 7.30\left(\mathrm{t}, \mathrm{J}=8.0 \mathrm{~Hz}, \mathrm{H}_{\mathrm{f}}\right), 6.85\left(\mathrm{~d}, \mathrm{~J}=7.5 \mathrm{~Hz}, \mathrm{H}_{\mathrm{b}}+\mathrm{H}_{\mathrm{g}}\right.$ ), $5.19\left(\mathrm{~s}, 1 \mathrm{H}, \mathrm{H}_{\mathrm{h}}\right), 4.00\left(\mathrm{~s}, 3 \mathrm{H}, 3 \mathrm{H}_{\mathrm{a}}\right)$.

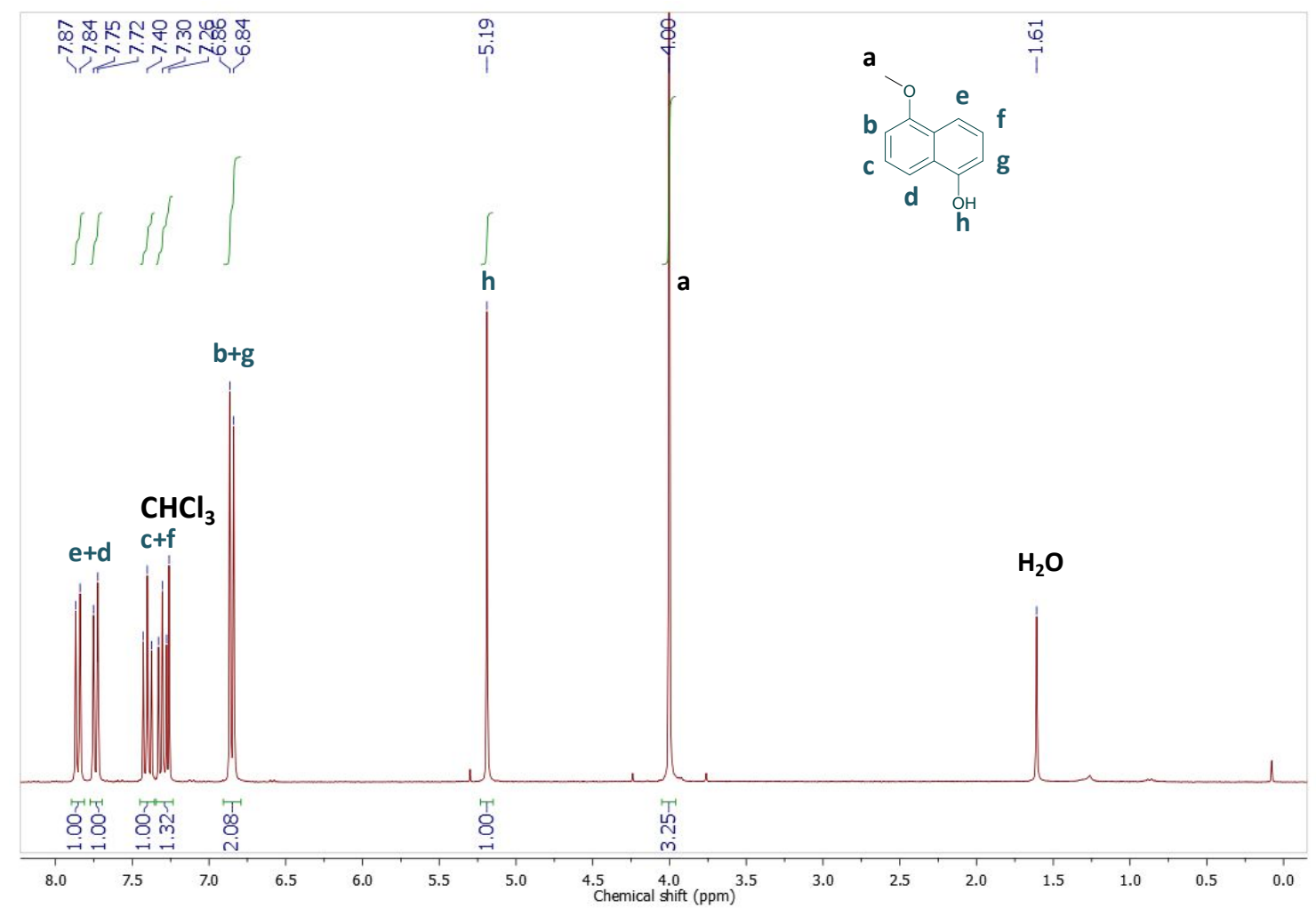

Figure S1. ${ }^{1} \mathrm{H}$ NMR spectrum of 5-methoxynaphthalen-1-ol (a) in $\mathrm{CDCl}_{3}$

${ }^{13} \mathrm{C}$ NMR $\left(75 \mathrm{MHz}, \mathrm{CDCl}_{3}\right) \delta(\mathrm{ppm})=155.5,151.3,127.1,125.5,125.4,125.3,114.1$,

113.8, 109.6, 104.6, 55.7.

$D S Q: M_{\exp }=173.8 \mathrm{~g} / \mathrm{mol}, M_{\mathrm{th}}=174.07 \mathrm{~g} / \mathrm{mol}$. 
m.p. $136.1-138^{\circ} \mathrm{C}$.

\section{2-(4-((5-methoxynaphthalen-1-yl)oxy)butyl)isoindoline-1,3-dione (b):}

In a $250 \mathrm{~mL}$ three-necked round bottom flask equipped with a stirring bar and a condenser, (a) (2.51 g, $14.4 \mathrm{mmol}, 1$ eq.) and potassium carbonate $(2.23 \mathrm{~g}, 16.1 \mathrm{mmol}$, 1.1 eq.) were dissolved in dimethylformamide (DMF, $150 \quad \mathrm{~mL}) . \quad \mathrm{N}-(4-$ bromobutyl)phthalimide $(5.71 \mathrm{~g}, 20.3 \mathrm{mmol}, 1.4$ eq.) was added to the reaction mixture and the flask was purged with argon. The reaction mixture was stirred for $24 \mathrm{~h}$ under reflux.

DMF was removed under vacuum and the resulting brown oil was dissolved in $\mathrm{CH}_{2} \mathrm{Cl}_{2}$ and filtered through dicalite. The filtrate was concentrated and the crude product was purified on a silica gel chromatography using a $7 / 3$ mixture of dichloromethane and petroleum ether as eluent giving a white powder $(4.3 \mathrm{~g}, 11.5 \mathrm{mmol}, 79 \%$ yield).

${ }^{1} \mathrm{H}$ NMR $\left(300 \mathrm{MHz}, \mathrm{CDCl}_{3}\right)$, Figure S2, $\delta(\mathrm{ppm})=7.86-7.67\left(\mathrm{~m}, \mathrm{H}_{\mathrm{e}}+\mathrm{H}_{\mathrm{d}}+2 \mathrm{H}_{1}+2 \mathrm{H}_{\mathrm{m}}\right)$, $7.36\left(\mathrm{t}, \mathrm{J}=7.8 \mathrm{~Hz}, \mathrm{H}_{\mathrm{f}}\right), 7.34\left(\mathrm{t}, \mathrm{J}=7.9 \mathrm{~Hz}, \mathrm{H}_{\mathrm{c}}\right), 6.83\left(\mathrm{~d}, \mathrm{~J}=7.5 \mathrm{~Hz}, \mathrm{H}_{\mathrm{b}}\right), 6.82(\mathrm{~d}, \mathrm{~J}=7.5$ $\left.\mathrm{Hz}, \mathrm{H}_{\mathrm{g}}\right), 4.17\left(\mathrm{t}, \mathrm{J}=5.4 \mathrm{~Hz}, 2 \mathrm{H}_{\mathrm{h}}\right), 4.00\left(\mathrm{~s}, \mathrm{H}_{\mathrm{a}}\right), 3.83\left(\mathrm{t}, \mathrm{J}=6.5 \mathrm{~Hz}, 2 \mathrm{H}_{\mathrm{k}}\right), 2.00\left(\mathrm{~m}, 2 \mathrm{H}_{\mathrm{i}}+\right.$ $\left.2 \mathrm{H}_{\mathrm{j}}\right)$. 


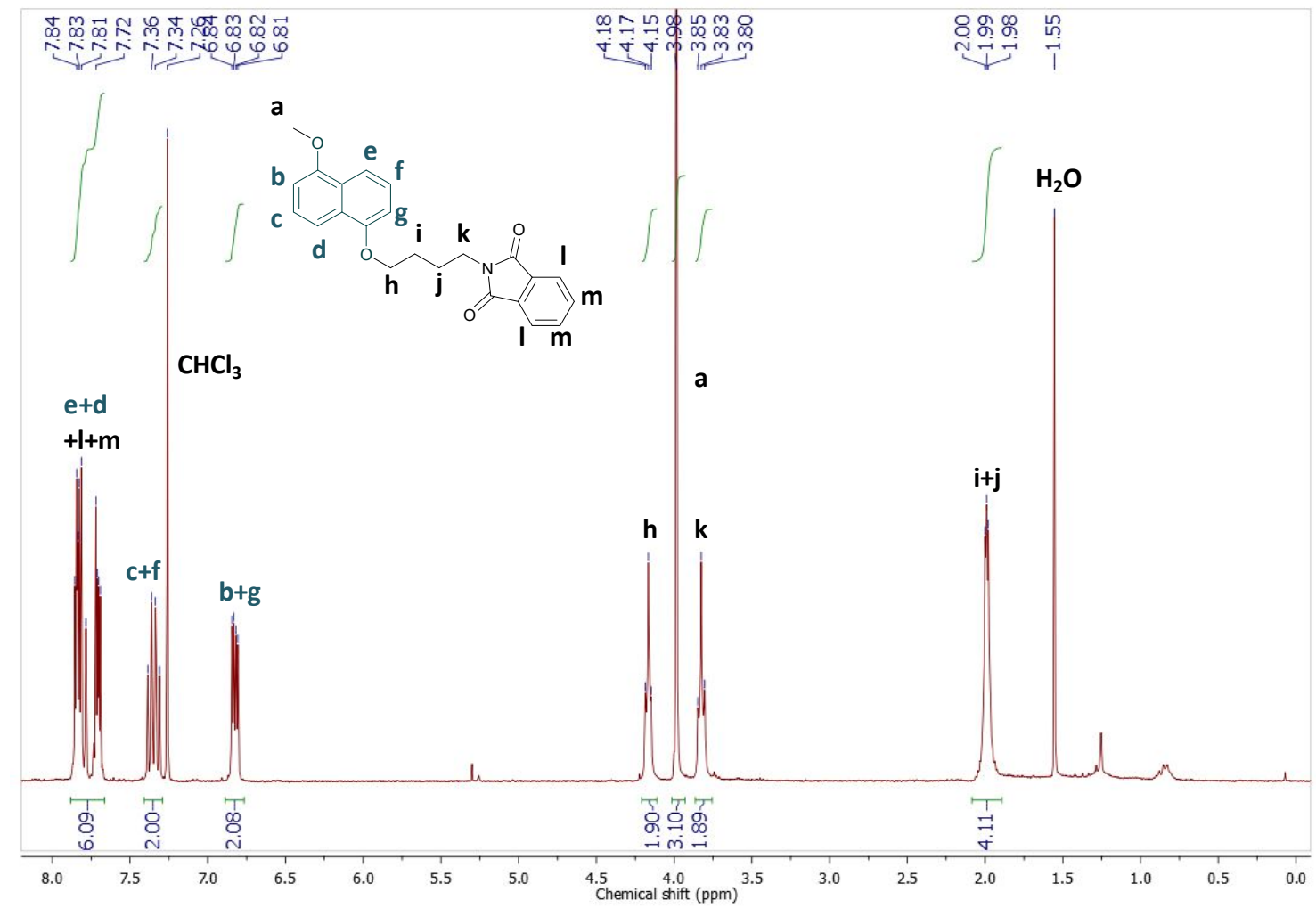

Figure S2. ${ }^{1} \mathrm{H}$ NMR spectrum of 2-(4-((5-methoxynaphthalen-1-yl)oxy)butyl)isoindoline1,3-dione (b) in $\mathrm{CDCl}_{3}$

${ }^{13} \mathrm{C}$ NMR $\left(75 \mathrm{MHz}, \mathrm{CDCl}_{3}\right) \delta(\mathrm{ppm})=168.5,155.2,154.5,134.0,132.1,126.7,126.6$, $125.2,125.2,123.2,114.4,114.2,105.4,104.6,67.4,55.6,37.8,26.8,25.6$.

MALDI-TOF MS Dithranol (DIT+): $M_{\exp }=375.3 \mathrm{~g} / \mathrm{mol}\left(+\mathrm{H}^{+}\right), M_{\text {th }}=375.15 \mathrm{~g} / \mathrm{mol}$.

m.p. $159-160.7^{\circ} \mathrm{C}$. 


\section{4-((5-methoxynaphthalen-1-yl)oxy)butan-1-amine (c):}

In a $250 \mathrm{~mL}$ three-necked round bottom flask equipped with a stirring bar and a

condenser, (b) ( $3.76 \mathrm{~g}, 10 \mathrm{mmol}, 1$ eq.) was dissolved in $100 \mathrm{~mL}$ of ethanol absolute. The reaction flask purged with argon. Hydrazine hydrate, $50-60 \%$ in water, $(17 \mathrm{~mL}, 32.7 \mathrm{mmol}$, 33 eq.) was added to the reaction mixture with a large excess and the milky solution was stirred for $48 \mathrm{~h}$ under reflux. The yellow suspension was filtered through cotton wool and washed with cold ethanol. Ethanol was removed under vacuum. The crude product was dissolved in $\mathrm{CH}_{2} \mathrm{Cl}_{2}$ and filtered through cotton wool. $\mathrm{CH}_{2} \mathrm{Cl}_{2}$ was removed under vacuum giving a yellowish solid $(2.273 \mathrm{~g}, 9.3 \mathrm{mmol}, 93 \%$ yield $)$.

${ }^{1} \mathrm{H}$ NMR $\left(300 \mathrm{MHz}, \mathrm{CDCl}_{3}\right)$, Figure S3, $\delta(p p m)=7.87\left(\mathrm{~d}, \mathrm{~J}=8.7 \mathrm{~Hz}, \mathrm{H}_{\mathrm{e}}\right), 7.83(\mathrm{~d}, \mathrm{~J}=$ $\left.8.7 \mathrm{~Hz}, \mathrm{H}_{\mathrm{d}}\right), 7.37\left(\mathrm{t}, \mathrm{J}=7.8 \mathrm{~Hz}, \mathrm{H}_{\mathrm{f}}\right), 7.36\left(\mathrm{t}, \mathrm{J}=7.8 \mathrm{~Hz}, \mathrm{H}_{\mathrm{c}}\right), 6.84\left(\mathrm{~d}, \mathrm{~J}=7.5 \mathrm{~Hz}, \mathrm{H}_{\mathrm{b}}\right), 6.82$ $\left(\mathrm{d}, \mathrm{J}=7.6 \mathrm{~Hz}, \mathrm{H}_{\mathrm{g}}\right), 4.12\left(\mathrm{t}, \mathrm{J}=6.3 \mathrm{~Hz}, 2 \mathrm{H}_{\mathrm{h}}\right), 4.00\left(\mathrm{~s}, 3 \mathrm{H}_{\mathrm{a}}\right), 2.81\left(\mathrm{t}, \mathrm{J}=7.2 \mathrm{~Hz}, 2 \mathrm{H}_{\mathrm{k}}\right), 1.95$ $\left(\mathrm{m}, 2 \mathrm{H}_{\mathrm{i}}\right), 1.71\left(\mathrm{~m}, 2 \mathrm{H}_{\mathrm{j}}\right)$. 


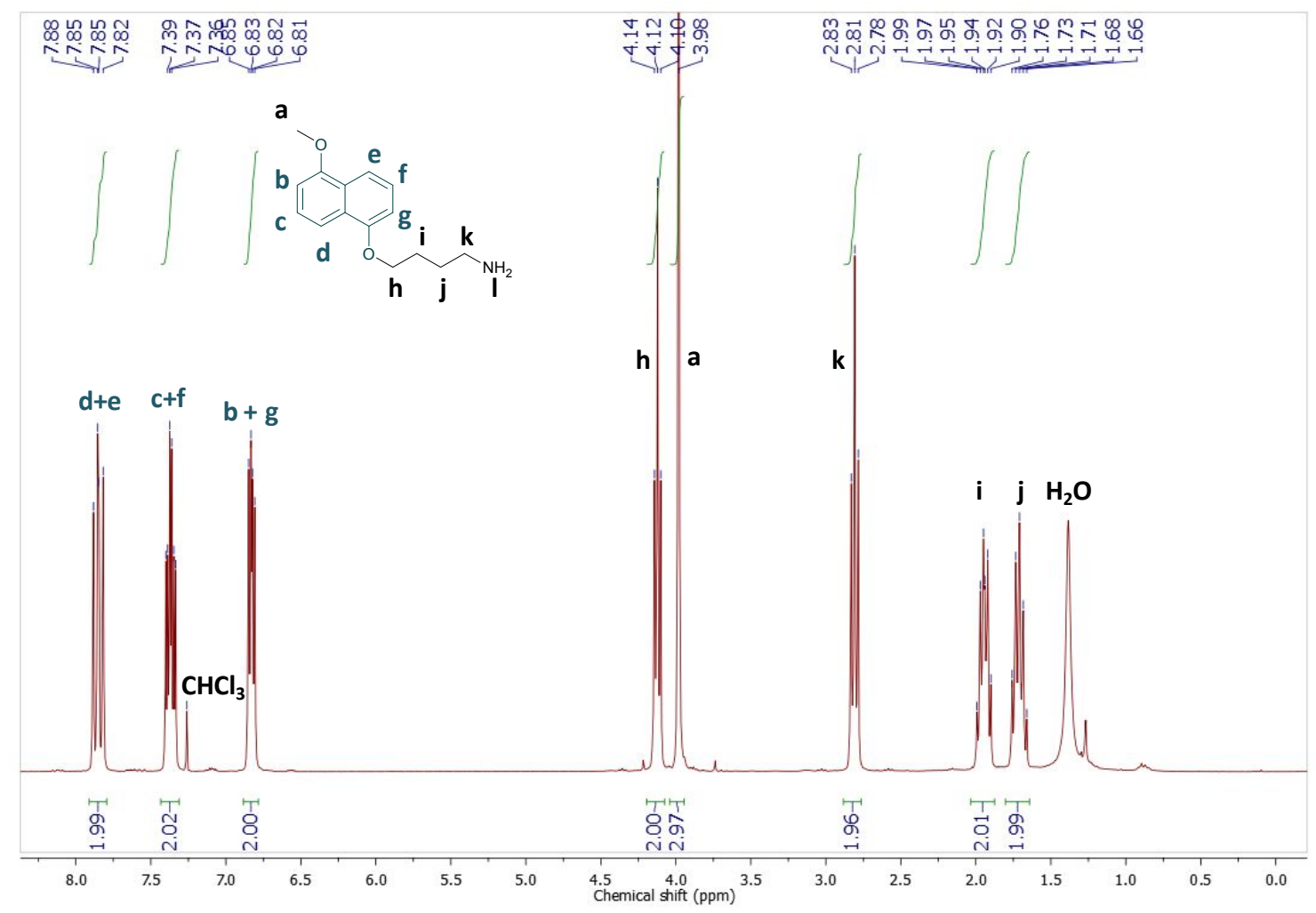

Figure S3. ${ }^{1} \mathrm{H}$ NMR spectrum of 4-((5-methoxynaphthalen-1-yl)oxy)butan-1-amine (c) in $\mathrm{CDCl}_{3}$

${ }^{13} \mathrm{C} \operatorname{NMR}\left(75 \mathrm{MHz}, \mathrm{CDCl}_{3}\right) \delta(\mathrm{ppm})=155.3,154.6,126.8,126.7,125.3,125.2,114.4$

$114.1,105.4,104.6,68.0,55.6,42.2,30.7,26.9$.

$D S Q: M_{\exp }=245.0 \mathrm{~g} / \mathrm{mol}, M_{\mathrm{th}}=245.14 \mathrm{~g} / \mathrm{mol}$.

m.p. $64-74{ }^{\circ} \mathrm{C}$. 
(1-(2,4-dimethyl-5-nitrophenyl)-3-(4-((5-methoxynaphthalen-1-yl)oxy)butyl)urea) (d):

In a $50 \mathrm{~mL}$ round bottom flask with a stirring bar, 2,4-dimethyl-5-nitroaniline $(0.65 \mathrm{~g}, 3.9$

mmol, 1 eq.) and $N, N$-diisopropylethylamine $(0.74 \mathrm{~mL}, 4.3 \mathrm{mmol}, 1.1$ eq. $)$ were dissolved

in dry $\mathrm{CH}_{2} \mathrm{Cl}_{2}$ under argon. This first solution was then transferred at room temperature

via syringe pump ( $\left.3.5 \mathrm{~mL} . \mathrm{h}^{-1}\right)$ to a stirred solution of triphosgene $(0.45 \mathrm{~g}, 1.5 \mathrm{mmol}, 0.39$

eq.) in $8 \mathrm{~mL}$ of dry $\mathrm{CH}_{2} \mathrm{Cl}_{2}$ placed in a schlenk tube under argon. The solution was stirred

for one hour and a second solution containing (c) $(1.01 \mathrm{~g}, 4.1 \mathrm{mmol}, 1.05$ eq.) and $\mathrm{N}, \mathrm{N}-$

diisopropylethylamine $\left(0.8 \mathrm{~mL}, 4.6 \mathrm{mmol}, 1.2\right.$ eq.) in $8 \mathrm{~mL}$ of dry $\mathrm{CH}_{2} \mathrm{Cl}_{2}$ was added

quickly via a double-tipped syringe and stirred overnight at room temperature. FT-IR

confirmed the disappearance of the isocyanate function $\left(\sim 2270 \mathrm{~cm}^{-1}\right) . \mathrm{CH}_{2} \mathrm{Cl}_{2}$ was

removed under vacuum of the clear brownish-green reaction mixture. The oily residue

was dissolved in ethyl acetate and washed successively with $10 \% \mathrm{KHSO}_{4}$ solution, $5 \%$

$\mathrm{NHCO}_{3}$, brine and water. The organic layer was concentrated under vacuum and the desired compound was recrystallized in acetonitrile giving a light yellowish powder (1.475

g, $3.37 \mathrm{mmol}, 87 \%$ yield). 
${ }^{1} \mathrm{H}$ NMR $\left(300 \mathrm{MHz}\right.$, DMSO-d $\left.\mathrm{d}_{6}\right)$, Figure S4, $\delta(\mathrm{ppm})=8.73\left(\mathrm{~s}, \mathrm{H}_{\mathrm{q}}\right), 7.91\left(\mathrm{~s}, \mathrm{H}_{\mathrm{m}}\right), 7.74(\mathrm{~d}$, $\left.J=8.4 \mathrm{~Hz}, \mathrm{H}_{\mathrm{d}}\right), 7.69\left(\mathrm{~d}, \mathrm{~J}=8.4 \mathrm{~Hz}, \mathrm{H}_{\mathrm{e}}\right), 7.38\left(\mathrm{t}, \mathrm{J}=8.1 \mathrm{~Hz}, \mathrm{H}_{\mathrm{f}}\right), 7.37\left(\mathrm{t}, \mathrm{J}=8.1 \mathrm{~Hz}, \mathrm{H}_{\mathrm{c}}\right)$, $7.22\left(\mathrm{~s}, \mathrm{H}_{\mathrm{o}}\right), 6.97\left(\mathrm{~d}, \mathrm{~J}=7.5 \mathrm{~Hz}, \mathrm{H}_{\mathrm{b}}+\mathrm{H}_{\mathrm{g}}\right), 6.84\left(\mathrm{t}, \mathrm{J}=5.4 \mathrm{~Hz}, \mathrm{H}_{\mathrm{l}}\right), 4.16\left(\mathrm{t}, \mathrm{J}=6.2 \mathrm{~Hz}, 2 \mathrm{H}_{\mathrm{h}}\right)$, $3.94\left(\mathrm{~s}, 3 \mathrm{H}_{\mathrm{a}}\right), 3.24\left(\mathrm{q}, \mathrm{J}=6.3 \mathrm{~Hz}, 2 \mathrm{H}_{\mathrm{k}}\right), 2.42\left(\mathrm{~s}, 3 \mathrm{H}_{\mathrm{p}}\right), 2.23\left(\mathrm{~s}, 3 \mathrm{H}_{\mathrm{n}}\right), 1.90\left(\mathrm{~m}, 2 \mathrm{H}_{\mathrm{i}}\right), 1.71$ $\left(m, 2 \mathrm{H}_{\mathrm{j}}\right)$.

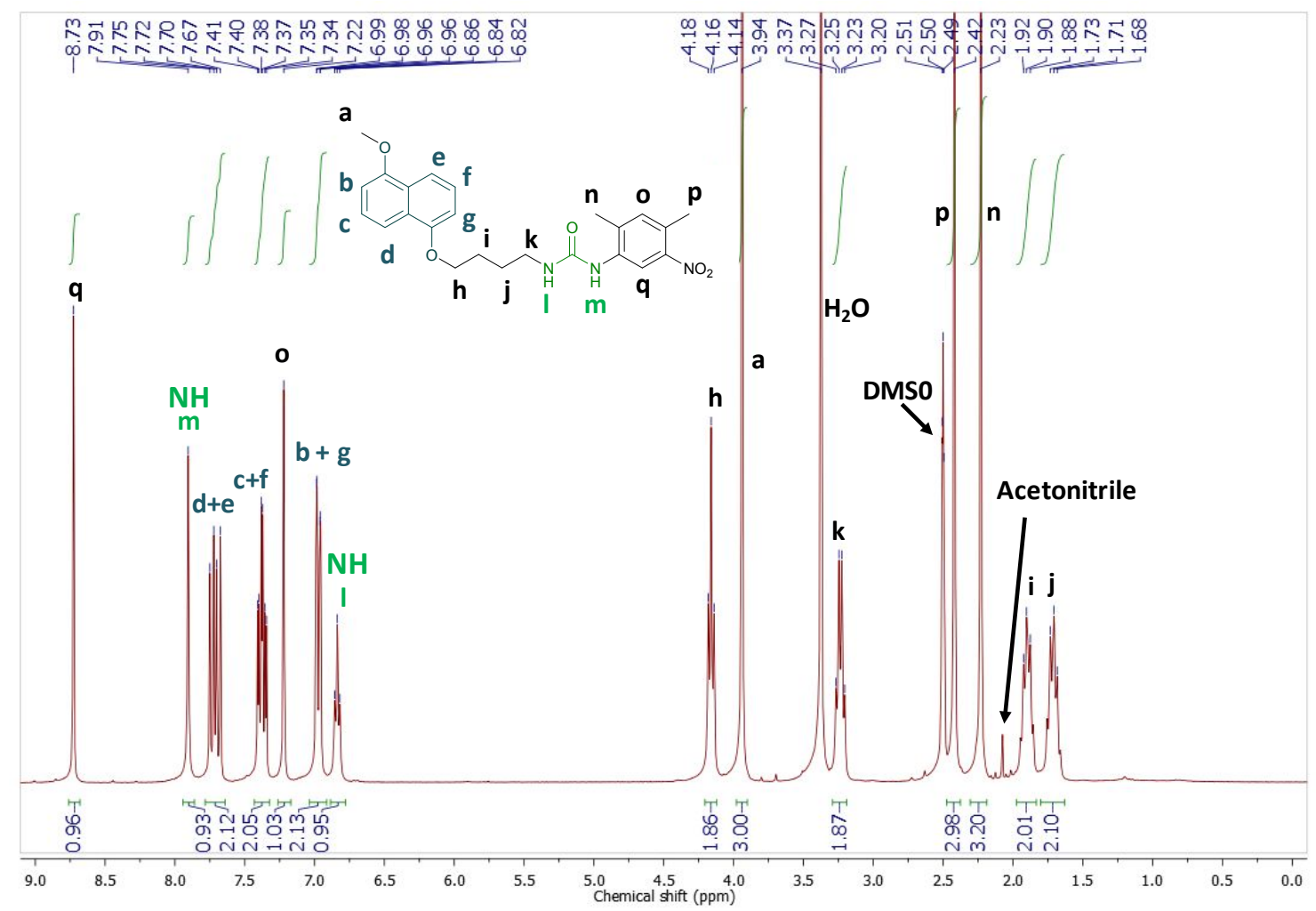

Figure S4. ${ }^{1} \mathrm{H} \quad$ NMR spectrum of (1-(2,4-dimethyl-5-nitrophenyl)-3-(4-((5methoxynaphthalen-1-yl)oxy)butyl)urea) (d) in DMSO-d 6 
${ }^{13} \mathrm{C}$ NMR $\left(75 \mathrm{MHz}\right.$, DMSO-d $\left.\mathrm{d}_{6}\right) \delta(\mathrm{ppm})=155.1,154.7,154.0,146.5,137.3,134.0$, 132.2, 126.0, 125.9, 125.5, 125.4, 125.3, 114.3, 113.6, 113.5, 105.8, 105.0, 67.5, 55.6, $38.9,26.6,26.3,19.3,17.8$.

MALDI-TOF MS Trans-2-[3-(4-tert-Butylphenyl)-2-methyl-2-propenylidene] malononitrile (DCTB ${ }^{+}$: $M_{\exp }=437.5 \mathrm{~g} / \mathrm{mol}\left(\right.$ with $\left.\mathrm{H}^{+}\right), \mathrm{M}_{\mathrm{th}}=437.20 \mathrm{~g} / \mathrm{mol}$. m.p. $161-163{ }^{\circ} \mathrm{C}\left(\mathrm{P}_{\mathrm{atm}}\right)$.

(1-(5-amino-2,4-dimethylphenyl)-3-(4-((5-methoxynaphthalen-1-yl)oxy)butyl)urea) (e):

In a $250 \mathrm{~mL}$ three-necked round bottom flask with a stirring bar, (d) $(3.00 \mathrm{~g}, 6.9 \mathrm{mmol}$, 1 eq.) and $10 \% \mathrm{Pd}$ on carbon ( $0.39 \mathrm{~g}, 0.36 \mathrm{mmol}, 0.05$ eq.) were added. The reaction flask was purged with argon and the solids were dissolved in $160 \mathrm{~mL}$ of a $1 / 1$ mixture of dry tetrahydrofuran (THF) and methanol. The reaction mixture was stirred for four hours at $40^{\circ} \mathrm{C}$ under hydrogen atmosphere then filtered through dicalite. The solvent was removed under vacuum giving a white powder $(2.47 \mathrm{~g}, 6.1 \mathrm{mmol}, 88 \%$ yield). This compound was used without further purification. 
${ }^{1} \mathrm{H}$ NMR $\left(300 \mathrm{MHz}\right.$, DMSO-d $\left.\mathrm{d}_{6}\right)$, Figure S5, $\delta(\mathrm{ppm})=7.75\left(\mathrm{~d}, \mathrm{~J}=8.4 \mathrm{~Hz}, \mathrm{H}_{\mathrm{e}}\right), 7.70(\mathrm{~d}, \mathrm{~J}$ $\left.=8.4 \mathrm{~Hz}, \mathrm{H}_{\mathrm{d}}\right), 7.40\left(\mathrm{t}, \mathrm{J}=8.1 \mathrm{~Hz}, \mathrm{H}_{\mathrm{c}}\right), 7.38\left(\mathrm{t}, \mathrm{J}=8.1 \mathrm{~Hz}, \mathrm{H}_{\mathrm{f}}\right), 7.33(\mathrm{~s}, \mathrm{H}), 7.09\left(\mathrm{~s}, \mathrm{H}_{\mathrm{o}}\right), 6.97$ $\left(\mathrm{d}, \mathrm{J}=7.8 \mathrm{~Hz}, \mathrm{H}_{\mathrm{b}}+\mathrm{H}_{\mathrm{g}}\right), 6.65\left(\mathrm{~s}, \mathrm{H}_{\mathrm{q}}\right), 6.42\left(\mathrm{t}, \mathrm{J}=5.5 \mathrm{~Hz}, \mathrm{H}_{\mathrm{l}}\right), 4.51\left(\mathrm{~s}, 2 \mathrm{H}_{\mathrm{r}}\right), 4.15(\mathrm{t}, \mathrm{J}=6.2$ $\left.\mathrm{Hz}, 2 \mathrm{H}_{\mathrm{h}}\right), 3.94\left(\mathrm{~s}, 3 \mathrm{H}_{\mathrm{a}}\right), 3.19\left(\mathrm{q}, \mathrm{J}=6.3 \mathrm{~Hz}, 2 \mathrm{H}_{\mathrm{k}}\right), 2.00\left(\mathrm{~s}, 3 \mathrm{H}_{\mathrm{n}}\right), 1.96\left(\mathrm{~s}, 3 \mathrm{H}_{\mathrm{p}}\right), 1.89(\mathrm{~m}$, $\left.2 \mathrm{H}_{\mathrm{i}}\right), 1.67\left(\mathrm{~m}, 2 \mathrm{H}_{\mathrm{j}}\right)$.

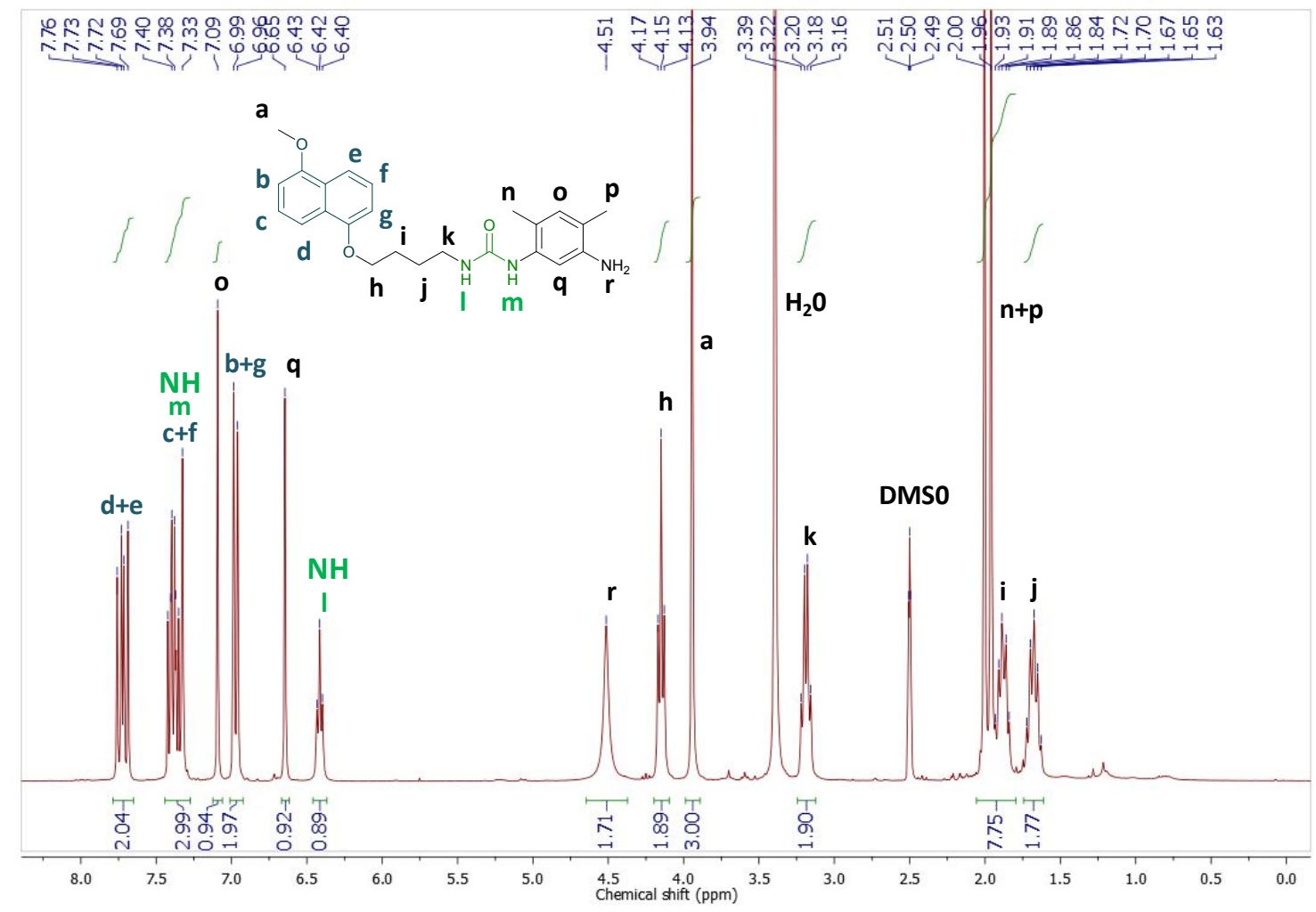

Figure S5. ${ }^{1} \mathrm{H} \quad \mathrm{NMR}$ spectrum of (1-(5-amino-2,4-dimethylphenyl)-3-(4-((5methoxynaphthalen-1-yl)oxy)butyl)urea) (e) in DMSO-d 6 
${ }^{13} \mathrm{C}$ NMR $(75 \mathrm{MHz}$, DMSO-d 6 ) $\delta(\mathrm{ppm})=155.6,154.7,154.0,144.4,136.2,131.3$, 126.0, 125.9, 125.6, 125.5, 115.4, 114.9, 113.7, 113.5, 107.9, 105.8, 105.0, 67.6, 55.6, $38.9,26.8,26.3,16.9,16.8$.

ESI: $M_{\exp }=408.1 \mathrm{~g} / \mathrm{mol}\left(\right.$ with $\left.\mathrm{H}^{+}\right), M_{\text {th }}=407.22 \mathrm{~g} / \mathrm{mol}$.

m.p. $162.4-163.4^{\circ} \mathrm{C}$.

\section{(3-nitrophenyl 2-bromo-2-methylpropanoate) (f):}

In a $100 \mathrm{~mL}$ schlenk tube with a stirring bar, 3-nitrophenol $(2.001 \mathrm{~g}, 14.4 \mathrm{mmol}, 1 \mathrm{eq}$. was added and flushed with argon before addition of dry THF $(40 \mathrm{~mL})$ and triethylamine (2.2 $\mathrm{mL}, 15.8 \mathrm{mmol}, 1.1$ eq.). To the clear orange reaction mixture, 2-bromoisobutyryl bromide (1.9 mL, $15 \mathrm{mmol}, 1.1$ eq.) was added dropwise and the reaction mixture was stirred overnight at room temperature. A white precipitate corresponding to triethylammonium bromide was removed by filtration and rinsed with THF. The filtrate was concentrated under vacuum and recrystallized in methanol giving a white powder (3.57 g, $12.4 \mathrm{mmol}, 86 \%$ yield). 
${ }^{1} \mathrm{H}$ NMR $\left(300 \mathrm{MHz}, \mathrm{CDCl}_{3}\right)$, Figure S6, $\delta(\mathrm{ppm})=8.16\left(\mathrm{~m}, \mathrm{H}_{\mathrm{t}}\right), 8.04\left(\mathrm{t}, \mathrm{J}=2.1 \mathrm{~Hz}, \mathrm{H}_{\mathrm{w}}\right)$,

$7.61\left(\mathrm{t}, \mathrm{J}=8.1 \mathrm{~Hz}, \mathrm{H}_{\mathrm{u}}\right), 7.51\left(\mathrm{~m}, \mathrm{H}_{\mathrm{v}}\right), 2.09\left(\mathrm{~s}, 6 \mathrm{H}_{\mathrm{x}}\right)$.

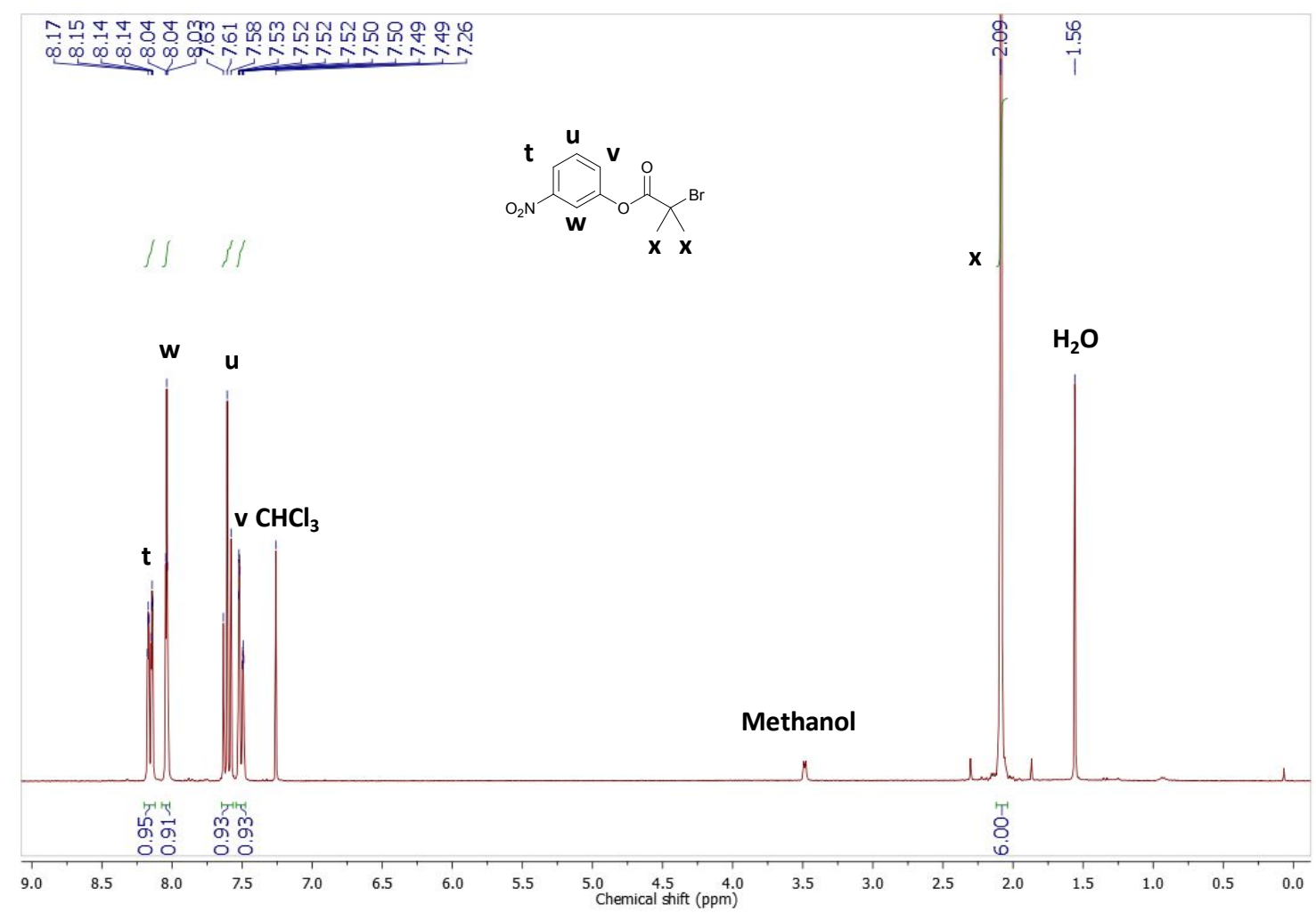

Figure S6. ${ }^{1} \mathrm{H}$ NMR spectrum of (3-nitrophenyl 2-bromo-2-methylpropanoate) (f) in $\mathrm{CDCl}_{3}$

${ }^{13} \mathrm{C}$ NMR $\left(75 \mathrm{MHz}, \mathrm{CDCl}_{3}\right) \delta(\mathrm{ppm})=169.7,151.0,148.8,130.3,127.7,121.2,117.0$,

$54.9,30.4,30.4$.

ESI: $M_{\exp }=288 \mathrm{~g} / \mathrm{mol}\left(\right.$ with $\left.\mathrm{H}^{+}\right), M_{\text {th }}=286.98 \mathrm{~g} / \mathrm{mol}$.

m.p. $90.6-91.5^{\circ} \mathrm{C}$. 


\section{(3-aminophenyl 2-bromo-2-methylpropanoate) (g):}

In a $100 \mathrm{~mL}$ three necked round bottom flask equipped with a stirring bar and a condenser, (f) (2.750 g, $9.55 \mathrm{mmol}, 1$ eq.) and tin(II) chloride dihydrate (10.4496 g, 48.5 $\mathrm{mmol}, 4.8$ eq.) were dissolved in ethyl acetate $(50 \mathrm{~mL})$. The clear yellowish solution was stirred under reflux for $1 \mathrm{~h} 30$. Ethyl acetate was then removed under vacuum. The crude product was purified by flash chromatography with $\mathrm{CH}_{2} \mathrm{Cl}_{2}$ as eluent giving a slightly brown powder ( $1.4 \mathrm{~g}, 5.42 \mathrm{mmol}, 57 \%$ yield). The product was stored at $-18{ }^{\circ} \mathrm{C}$ under argon to limit its degradation over time.

${ }^{1} \mathrm{H}$ NMR $\left(300 \mathrm{MHz}, \mathrm{DMSO}-\mathrm{d}_{6}\right)$, Figure S7, $\delta(\mathrm{ppm})=7.04\left(\mathrm{t}, \mathrm{J}=8 \mathrm{~Hz}, \mathrm{H}_{\mathrm{u}}\right), 6.46\left(\mathrm{~m}, \mathrm{H}_{\mathrm{v}}\right)$, $6.31\left(\mathrm{t}, \mathrm{J}=2.1 \mathrm{~Hz}, \mathrm{H}_{\mathrm{w}}\right), 6.24\left(\mathrm{~m}, \mathrm{H}_{\mathrm{t}}\right), 5.36\left(\mathrm{~s}, 2 \mathrm{H}_{\mathrm{s}}\right), 2.05\left(\mathrm{~s}, 6 \mathrm{H}_{\mathrm{x}}\right)$. 


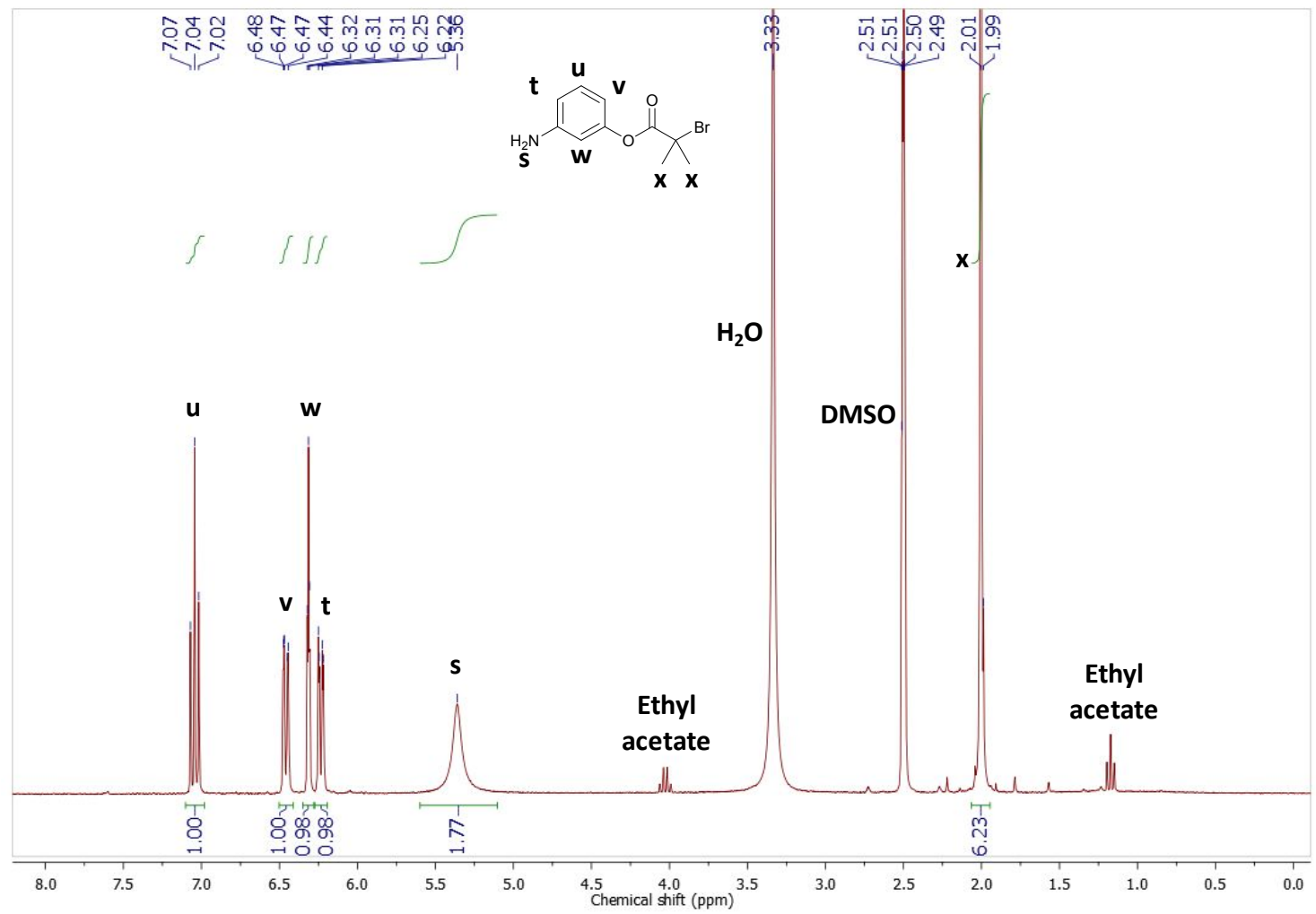

Figure S7. ${ }^{1} \mathrm{H}$ NMR spectrum of (3-aminophenyl 2-bromo-2-methylpropanoate) (g) in DMSO-d 6

${ }^{13} \mathrm{C} \mathrm{NMR}\left(300 \mathrm{MHz}, \mathrm{CDCl}_{3}\right) \delta(\mathrm{ppm})=170.4,151.9,147.9,130.2,113.0,110.8,107.7$ $55.7,30.8$.

$D S Q: M_{\exp }=256.8 \mathrm{~g} / \mathrm{mol}, M_{\mathrm{th}}=257.01 \mathrm{~g} / \mathrm{mol}$. 


\section{(3-(3-(5-(3-(4-((5-methoxynaphthalen-1-yl)oxy)butyl)ureido)-2,4-}

dimethylphenyl)ureido) phenyl 2-bromo-2-methylpropanoate) (h):

In a $50 \mathrm{~mL}$ round bottom flask with a stirring bar, $(\mathrm{g})(1.00 \mathrm{~g}, 3.9 \mathrm{mmol}, 1 \mathrm{eq}$.$) and \mathrm{N}, \mathrm{N}$ -

diisopropylethylamine $\left(0.8 \mathrm{~mL}, 4.6 \mathrm{mmol}, 1.2\right.$ eq.) were dissolved in dry $\mathrm{CH}_{2} \mathrm{Cl}_{2}$ under

argon. The clear yellowish solution was then transferred at room temperature thanks to a

syringe pump ( $\left.3.5 \mathrm{~mL} . \mathrm{h}^{-1}\right)$ to a stirred solution of triphosgene $(0.44 \mathrm{~g}, 1.5 \mathrm{mmol}, 0.38 \mathrm{eq}$.)

in $10 \mathrm{~mL}$ of dry $\mathrm{CH}_{2} \mathrm{Cl}_{2}$ placed in a schlenk tube under argon. After the addition, the

mixture was stirred for $1 \mathrm{~h}$ and a milky solution of $(\mathrm{e})(1.66 \mathrm{~g}, 4.1 \mathrm{mmol}, 1.05 \mathrm{eq}$.$) and$

$\mathrm{N}, \mathrm{N}$-diisopropylethylamine $\left(0.8 \mathrm{~mL}, 4.6 \mathrm{mmol}, 1.2 \mathrm{eq}\right.$.) in $8 \mathrm{~mL}$ of dry $\mathrm{CH}_{2} \mathrm{Cl}_{2}$ was added

quickly via a double-tipped syringe. The cloudy solution turned to a clear yellowish one

after $5 \mathrm{~min}$ and was stirred overnight at room temperature. FT-IR confirmed the

disappearance of the isocyanate function $\left(\sim 2270 \mathrm{~cm}^{-1}\right)$. The brownish organic layer was

concentrated under vacuum and precipitated in methanol. The solid was filtered and

washed with pentane giving a white powder $(2.06 \mathrm{~g}, 2.98 \mathrm{mmol}, 77 \%$ yield).

${ }^{1} \mathrm{H}$ NMR $\left(300 \mathrm{MHz}, \mathrm{DMSO}-\mathrm{d}_{6}\right)$, Figure $\mathrm{S} 8, \delta(\mathrm{ppm})=9.10\left(\mathrm{~s}, \mathrm{H}_{\mathrm{s}}\right), 8.09\left(\mathrm{~s}, \mathrm{H}_{\mathrm{q}}\right), 7.85(\mathrm{~s}$, $\left.H_{r}\right), 7.74\left(d, J=8.4 \mathrm{~Hz}, H_{d}\right), 7.69\left(d, J=8.4 \mathrm{~Hz}, H_{e}\right), 7.55\left(s, H_{m}+H_{w}\right), 7.37\left(m, H_{c}+H_{f}\right.$ 
$\left.+H_{u}\right), 7.16\left(d, J=8.1 \mathrm{~Hz}, H_{t}\right), 6.97\left(m, H_{b}+H_{g}\right), 6.92\left(s, H_{o}\right), 6.74\left(d, J=7.8 \mathrm{~Hz}, H_{v}\right)$,

$6.48\left(\mathrm{t}, \mathrm{J}=5.5 \mathrm{~Hz}, \mathrm{H}_{\mathrm{l}}\right), 4.16\left(\mathrm{t}, \mathrm{J}=6 \mathrm{~Hz}, 2 \mathrm{H}_{\mathrm{h}}\right), 3.94\left(\mathrm{~s}, 3 \mathrm{H}_{\mathrm{a}}\right), 3.20\left(\mathrm{q}, \mathrm{J}=5.7 \mathrm{~Hz}, 2 \mathrm{H}_{\mathrm{k}}\right)$,

$2.13\left(\mathrm{~s}, 3 \mathrm{H}_{\mathrm{n}}\right), 2.11\left(\mathrm{~s}, 3 \mathrm{H}_{\mathrm{p}}\right), 2.03\left(\mathrm{~s}, 6 \mathrm{H}_{\mathrm{x}}\right), 1.89\left(\mathrm{~m}, 2 \mathrm{H}_{\mathrm{i}}\right), 1.69\left(\mathrm{~m}, 2 \mathrm{H}_{\mathrm{j}}\right)$.

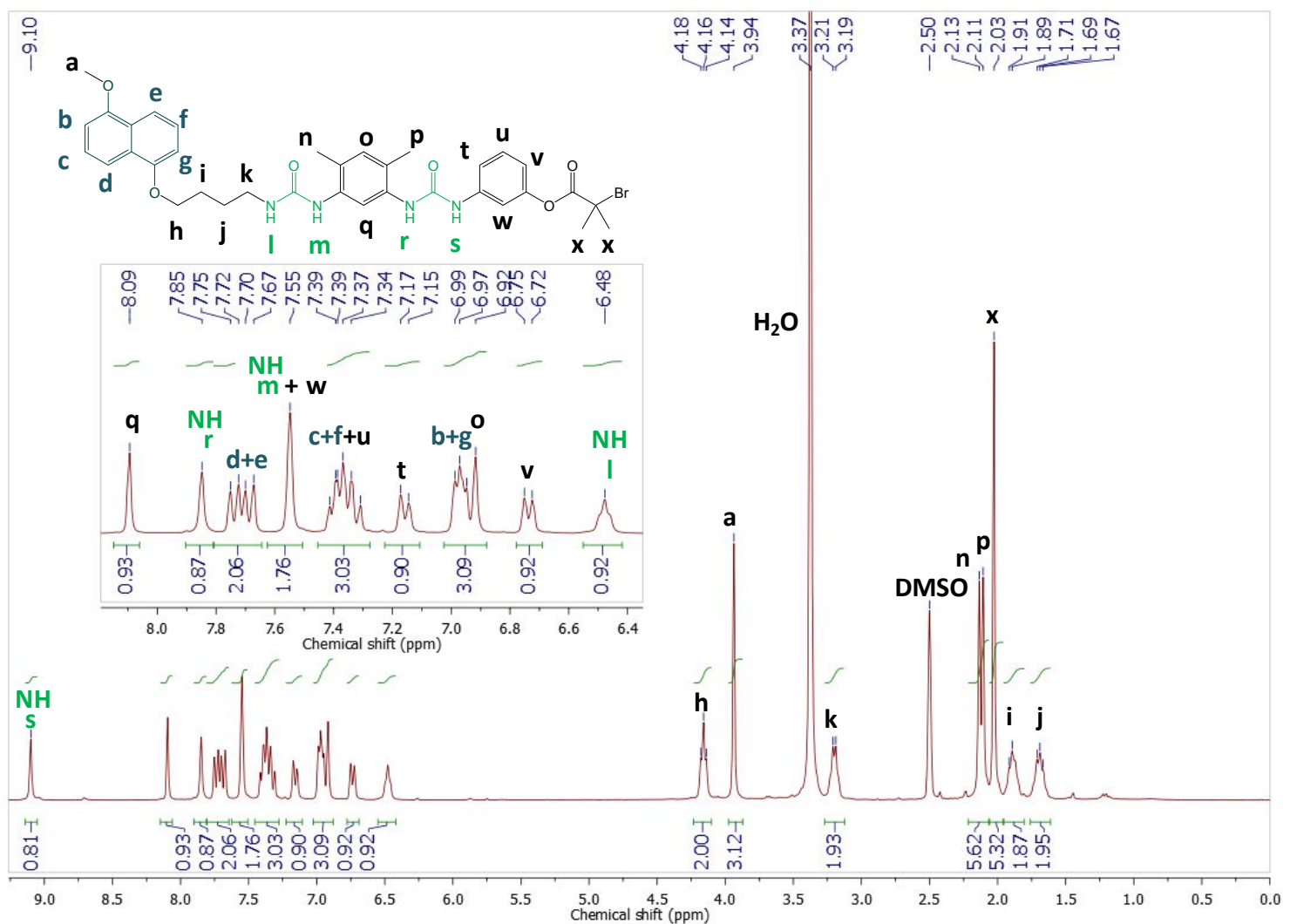

Figure S8. ${ }^{1} \mathrm{H} \quad$ NMR spectrum of (3-(3-(5-(3-(4-((5-methoxynaphthalen-1yl)oxy)butyl)ureido)-2,4-dimethylphenyl)ureido)phenyl 2-bromo-2-methylpropanoate) (h) in DMSO-d 6 
${ }^{13} \mathrm{C}$ NMR $\left(75 \mathrm{MHz}, \mathrm{DMSO}-\mathrm{d}_{6}\right) \delta(\mathrm{ppm})=169.6,155.5,154.7,154,0,152.6,150.8$,

141.1, 136.0, 134.7, 131.4, 129.7, 126.0, 125.9, 125.5, 125.5, 122.8, 122.6, 115.7, 115.5,

113.9, 113.7, 113.4, 110.5, 105.8, 105.0, 67.6, 57.2, 55.6, 30.0, 26.8, 26.3, 17.3, 17.2.

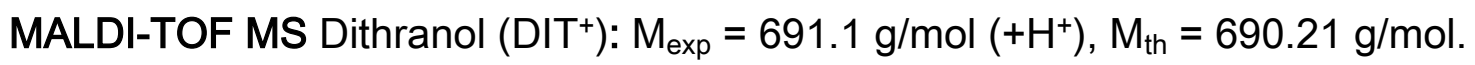

m.p. $183-184^{\circ} \mathrm{C}$.

\section{Synthesis of DAN-U $U_{2}-P H E A$ by SARA ATRP (according to Nicol et al. ${ }^{2}$ ) :}

The following $[\mathrm{HEA}]_{0} /[(\mathrm{h})]_{0} /[\text { ligand }]_{0} /\left[\mathrm{CuBr}_{2}\right]_{0}: 50 / 1 / 0.15 / 0.05$ molar ratio was used with

a volume ratio HEA / DMSO (25/75 (v/v)).

In a $20 \mathrm{~mL}$ vial with a stirring bar, (h) $(0.14 \mathrm{~g}, 0.21 \mathrm{mmol}, 1$ eq.) and 2-hydroxyethyl acrylate (1.20 g, $10 \mathrm{mmol}, 50 \mathrm{eq}$.) were dissolved in DMSO under argon. A copper wire $\mathrm{Cu}(0)$ (length $=1 \mathrm{~cm}$, diameter $=1.3 \mathrm{~mm})$, previously activated by sulfuric acid and carefully rinsed with water, was added as a catalyst. $\mathrm{CuBr}_{2}(0.010 \mathrm{mmol}, 0.05$ eq.) in degassed DMSO $(0.6 \mathrm{~mL})$ was added to the first mixture. The vial was then purged for 20 min by bubbling argon. The polymerization was initiated by transferring $\mathrm{Me}_{6} \mathrm{TREN}$ $(0.031 \mathrm{~g}, 0.15$ eq.) in degassed DMSO $(0.3 \mathrm{~mL})$ to the cloudy brownish reaction mixture 
placed in an oil bath at $50{ }^{\circ} \mathrm{C}$. The medium turned instantaneously to a clear light green solution. The polymerization was stopped after $28 \min ($ monomer conversion $=79 \%$ ) and the mixture was precipitated in $300 \mathrm{~mL}$ of diethyl ether. The PHEA derivative could not be separated from copper (II) traces by conventional chromatography column (either on silica or alumina) because of its high polarity. The recovered oily polymer was dissolved in $100 \mathrm{~mL}$ of water and stirred with a chelating resin (Dowex ${ }^{\circledR}$ M4195) for two days to remove copper traces $(\mathrm{Cu}(\mathrm{II}))$. The solution was then filtered and $0.980 \mathrm{~g}$ of viscous liquid was recovered after freeze drying.

${ }^{1} \mathrm{H}$ NMR $\left(400 \mathrm{MHz}\right.$, DMSO-d $\left.\mathrm{d}_{6}\right)$, Figure $\mathrm{S9}, \delta(\mathrm{ppm})=9.02\left(\mathrm{~s}, \mathrm{H}_{\mathrm{s}}\right), 8.06\left(\mathrm{~s}, \mathrm{H}_{\mathrm{q}}\right), 7.84(\mathrm{~s}$, $\left.\mathrm{H}_{\mathrm{r}}\right), 7.74\left(\mathrm{~d}, \mathrm{~J}=8.4 \mathrm{~Hz}, \mathrm{H}_{\mathrm{d}}\right), 7.69\left(\mathrm{~d}, \mathrm{~J}=8.4 \mathrm{~Hz}, \mathrm{H}_{\mathrm{e}}\right), 7.54\left(\mathrm{~s}, \mathrm{H}_{\mathrm{m}}\right), 7.43-7.24\left(\mathrm{~m}, \mathrm{H}_{\mathrm{c}}+\mathrm{H}_{\mathrm{f}}+\right.$ $\left.H_{u}+H_{w}\right), 7.20\left(m, ~, H_{t}\right), 6.97\left(m, H_{b}+H_{g}\right), 6.92\left(s, H_{o}\right), 6.67\left(m, H_{v}\right), 6.47(t, J=5.5 \mathrm{~Hz}$ $\left.\mathrm{H}_{\mathrm{I}}\right), 4.74\left(\mathrm{~s}, \mathrm{H}_{5} \times \mathrm{DP}_{\mathrm{n}}\right), 4.17\left(\mathrm{t}, \mathrm{J}=6 \mathrm{~Hz}, 2 \mathrm{H}_{\mathrm{h}}\right), 4.01\left(\mathrm{~s}, 2 \mathrm{H}_{3} \times \mathrm{DP}_{\mathrm{n}}\right), 3.94\left(\mathrm{~s}, 3 \mathrm{H}_{\mathrm{a}}\right), 3.55(\mathrm{~s}$, $\left.2 \mathrm{H}_{4} \times \mathrm{DP}_{\mathrm{n}}\right), 3.20\left(\mathrm{q}, \mathrm{J}=5.7 \mathrm{~Hz}, 2 \mathrm{H}_{\mathrm{k}}\right), 2.40-2.17\left(\mathrm{~m}, \mathrm{H}_{2} \times \mathrm{DP}_{\mathrm{n}}\right), 2.13\left(\mathrm{~s}, 3 \mathrm{H}_{\mathrm{n}}\right), 2.11\left(\mathrm{~s}, 3 \mathrm{H}_{\mathrm{p}}\right)$, 2.00-1.30(m, $\left.2 \mathrm{H}_{1} \times \mathrm{DP}_{\mathrm{n}}+2 \mathrm{H}_{\mathrm{i}}+2 \mathrm{H}_{\mathrm{j}}\right), 1.23\left(\mathrm{~m}, 6 \mathrm{H}_{\mathrm{x}}\right)$. 
A number average degree of polymerization $\mathrm{DP}_{\mathrm{n}} \approx 43$ was estimated by ${ }^{1} \mathrm{H}$ NMR using the aromatic proton signal at $6.92 \mathrm{ppm}\left(\mathrm{H}_{\mathrm{o}}\right)$ as a reference compared to the signal of the hydroxyl groups $\left(H_{5}\right)$ at $4.74 \mathrm{ppm}$ leading to $M_{n} \exp \approx 5700 \mathrm{~g} / \mathrm{mol}$.

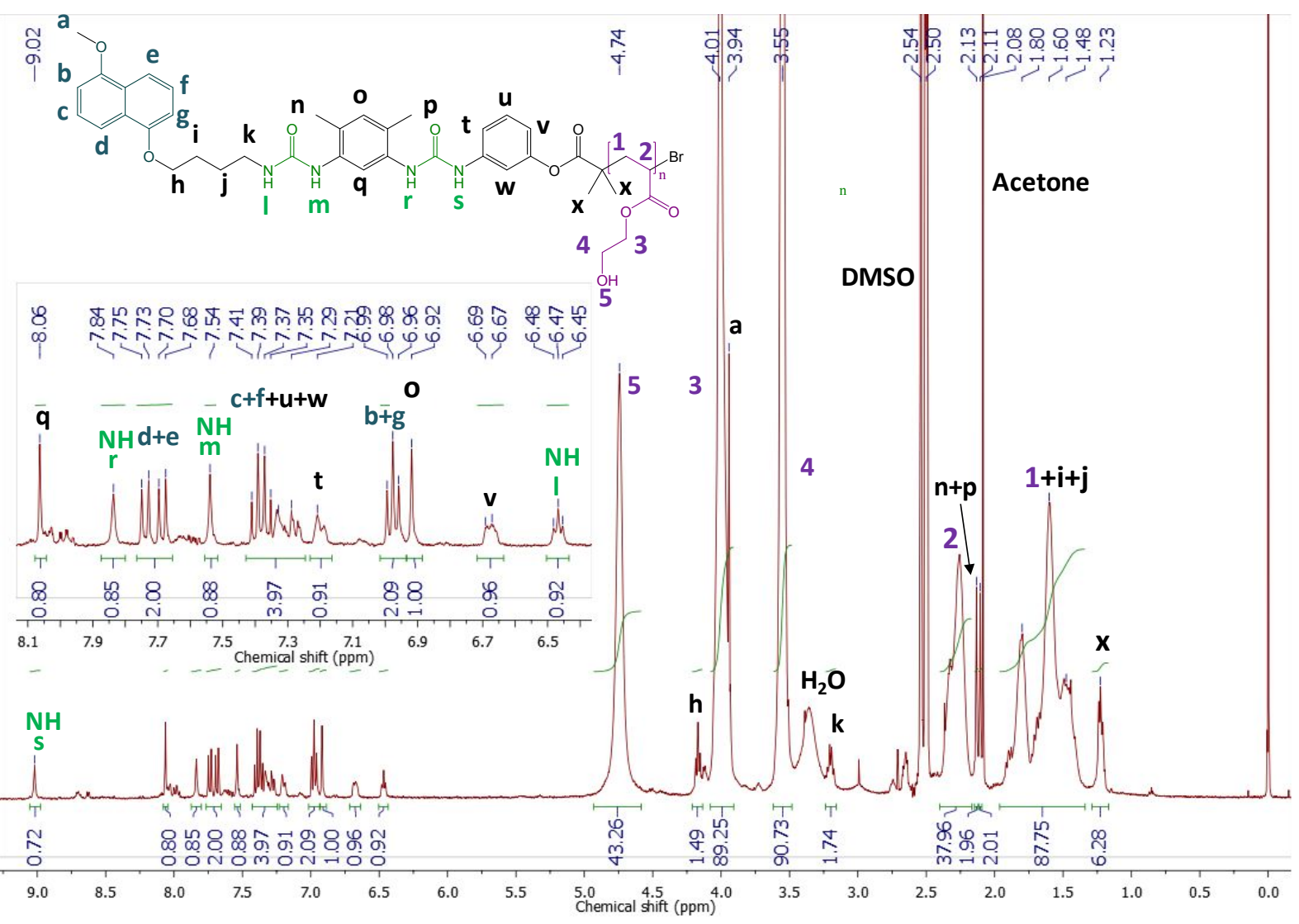

Figure S9. ${ }^{1} \mathrm{H}$ NMR spectrum of DAN- $\mathrm{U}_{2}-\mathrm{PHEA}$ in DMSO- $\mathrm{d}_{6}$

DAN- $\mathrm{U}_{2}$-PHEA was analyzed by size exclusion chromatography in $\mathrm{DMF} / \mathrm{LiBr}$ (Figure S10). The chromatogram shows a main peak corresponding to the expected polymer and 
a little shoulder probably indicating the occurrence of termination reactions leading to the coupling of two polymer chains. However, this second population remains very small (< $5 \mathrm{wt} \%)$ and the dispersity of the polymer is quite low. The molar masses and dispersity were evaluated in PMMA equivalents by integrating the whole SEC trace and gathered in Table S1.

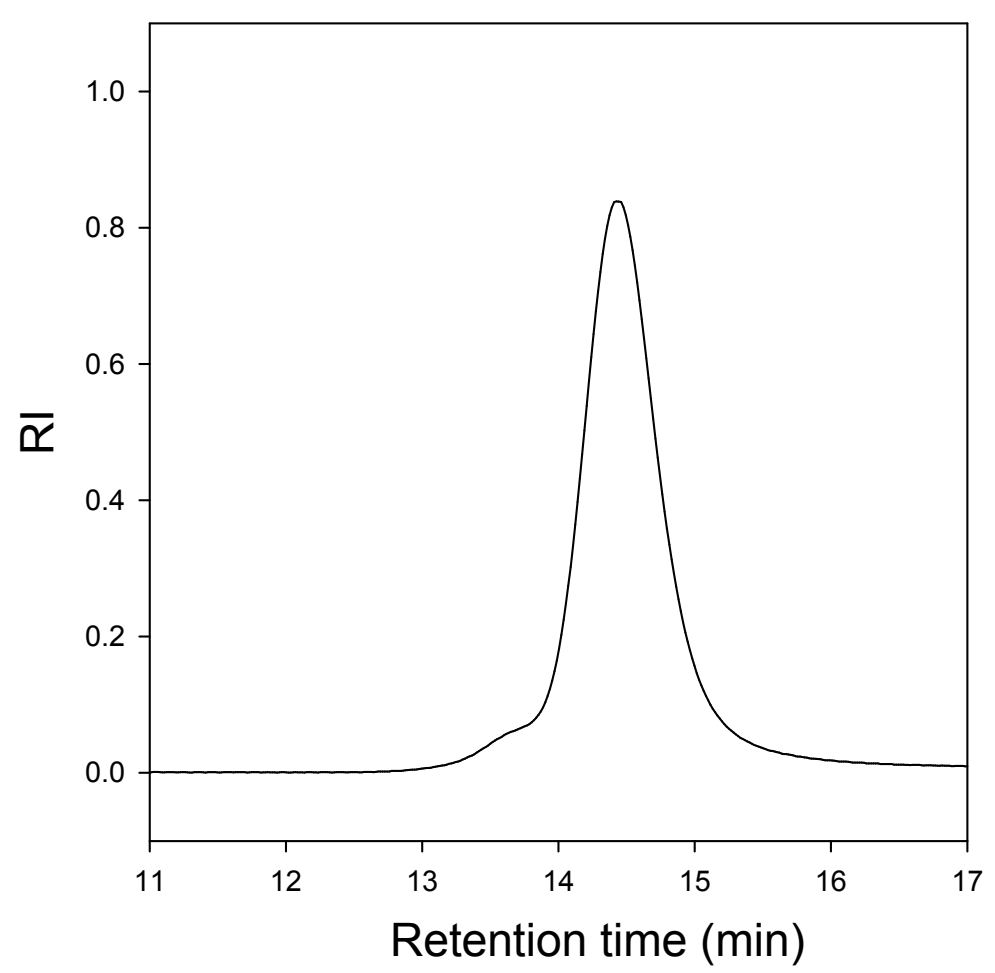

Figure S10. SEC chromatogram of $\mathrm{DAN}-\mathrm{U}_{2}$-PHEA solution in $\mathrm{DMF} / \mathrm{LiBr}$ 
Table S1. Molecular characteristics of DAN- $U_{2}-$ PHEA (theoretical $M_{n}=5300 \mathrm{~g} / \mathrm{mol}, D_{n}$

$=40)$

\begin{tabular}{|c|c|c|}
\cline { 2 - 3 } \multicolumn{1}{c|}{} & NMR & SEC \\
\hline $\mathrm{M}_{\mathrm{n}}$ & 5700 & 10200 \\
$(\mathrm{~g} / \mathrm{mol})$ & & \\
\hline $\mathrm{M}_{\mathrm{w}}$ & - & 11100 \\
$(\mathrm{~g} / \mathrm{mol})$ & & \\
\hline$Ð$ & - & 1.09 \\
\hline
\end{tabular}

a Measured in DMF+LiBr in PMMA-equivalents. 


\section{Miscibility of PEO and PHEA}

In order to assess the compatibility of PEO and PHEA, a 50/50 wt\% mixture of PEO $\left(\mathrm{M}_{n}\right.$ $=2000 \mathrm{~g} / \mathrm{mol}$; Aldrich $)$ and PHEA $\left(\mathrm{M}_{\mathrm{n}}=6000 \mathrm{~g} / \mathrm{mol}\right.$; synthesized according to a procedure described by Nicol et al. ${ }^{2}$ ) was made by co-precipitation of the polymers in diethyl ether from a dichloromethane solution. The resulting blend and the homopolymers were analyzed by DSC after drying. Figure $\mathbf{S 1 1}$ shows the thermograms obtained by cooling the samples from $+100{ }^{\circ} \mathrm{C}$ to $-100^{\circ} \mathrm{C}$ at a cooling rate $\mathrm{v}=20^{\circ} \mathrm{C} / \mathrm{min}$. A clear decrease of the PEO crystallization temperature $T_{c}$ (from 29.2 to $8.2{ }^{\circ} \mathrm{C}$ ) and crystallinity rate is observed upon mixing with PHEA (Fig. S11a). The blend also exhibits an intermediate glass transition temperature (Fig. S11b) indicating the miscibility of both polymers in the bulk. ${ }^{3}$ The calculation of the blend glass transition temperature according to the empirical

Fox equation ${ }^{4}$ gives $\mathrm{T}_{\mathrm{g} \text { (theo) }}=-45^{\circ} \mathrm{C}$, which is in agreement with the experimental value $\operatorname{Tg}_{(\text {exp })}=-51.5^{\circ} \mathrm{C}$. It can be concluded that PEO and PHEA chains of PEO-NDI- $\mathrm{U}_{2}$ and DAN- $U_{2}-$ PHEA respectively are compatible. 

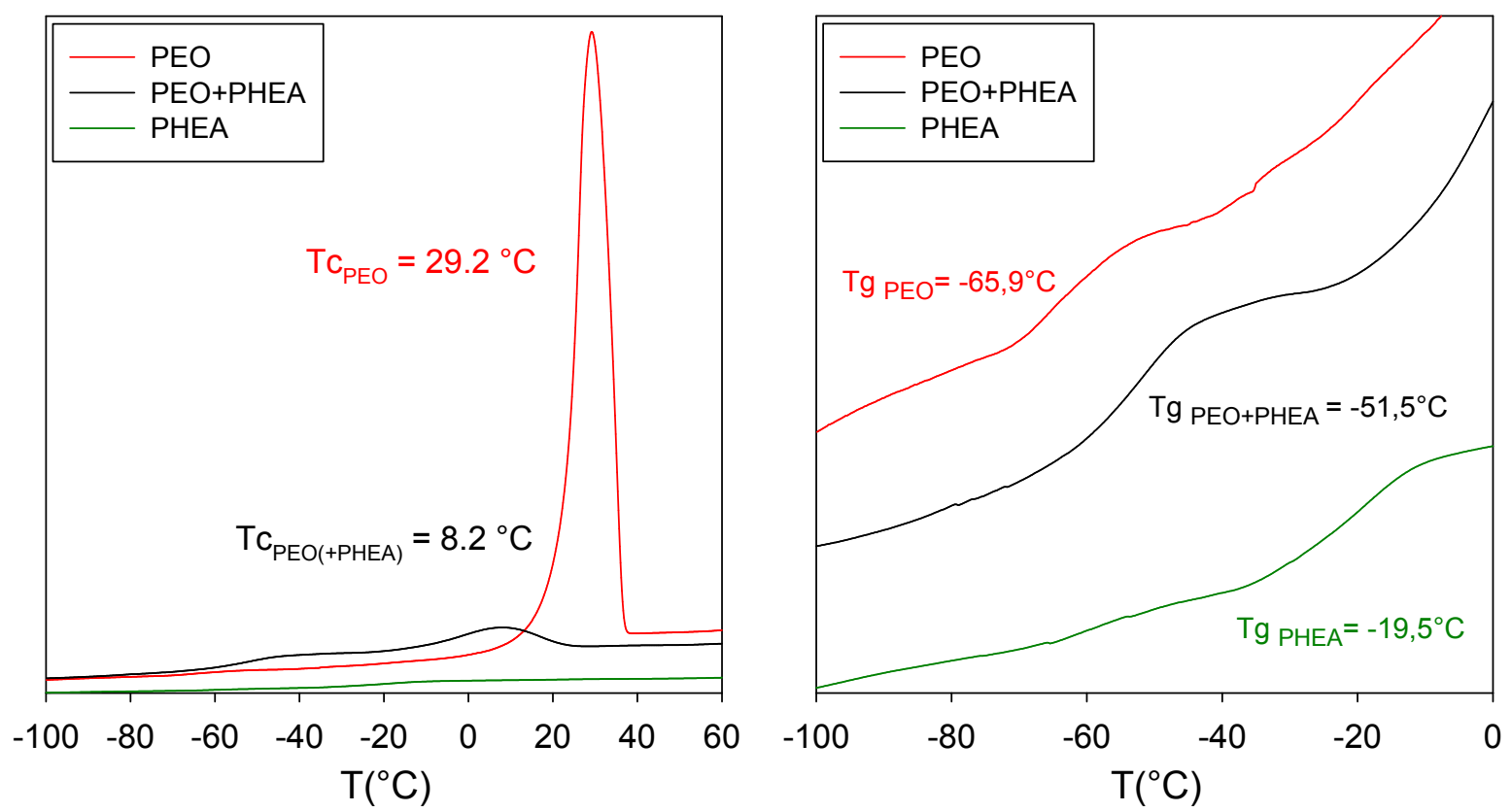

Figure S11. Thermograms of PEO, PHEA and PEO/PHEA (50/50 \%wt) blend at a cooling rate of $20^{\circ} \mathrm{C} / \mathrm{min}$. (a) Focus on the crystallization temperature of the PEO (normalized by the PEO wt \% in the sample). (b) Focus on the glass transition temperatures. Curves were vertically shifted for clarity. Exo up. 


\section{Characteristics of PEO-NDI- $\mathrm{U}_{2}$ and $\mathrm{DAN}-\mathrm{U}_{2}-\mathrm{PHEA}$ individual self-assemblies in}

water

PEO-NDI- $U_{2}$ self-assembly in water has been previously reported ${ }^{1}$. It was shown to form long cylinders of radius $R_{c}=5 \mathrm{~nm}$, exhibiting ca. 6 polymer chains in the cross section of the cylinder. SLS data (Figure S13, Table S2) and cryoTEM image (Figure S14 (a)) are summarized below.

\section{DAN-U - -PHEA}

DLS measurements of DAN- $\mathrm{U}_{2}$-PHEA in water show two populations of scatterers

(Figure S12). The slow mode of relaxation corresponded to an apparent hydrodynamic radius $R_{\text {app,slow }} \sim 60 \mathrm{~nm}$ whereas the fast mode gives $R_{\text {app,fast }}<10 \mathrm{~nm}$. The slow mode of relaxation contributed strongly to the DLS and SLS signals because of the large molecular weight of the corresponding particles. However, the fact that the fast mode of relaxation also contributed in spite of the much smaller radius (and therefore molecular weight) of the corresponding particles implied that the weight percentage of the slow mode could be neglected compared to that of the fast mode. The SLS and DLS data presented in the 
manuscript therefore correspond to the contribution of the fast mode of relaxation. A similar behavior has already been observed in the literature for many other selfassembling systems $\mathbf{s}^{5-8}$ and the same treatment was applied to get rid of the contribution of the large aggregates. This treatment gave results in agreement with cryoTEM (Figure S14).

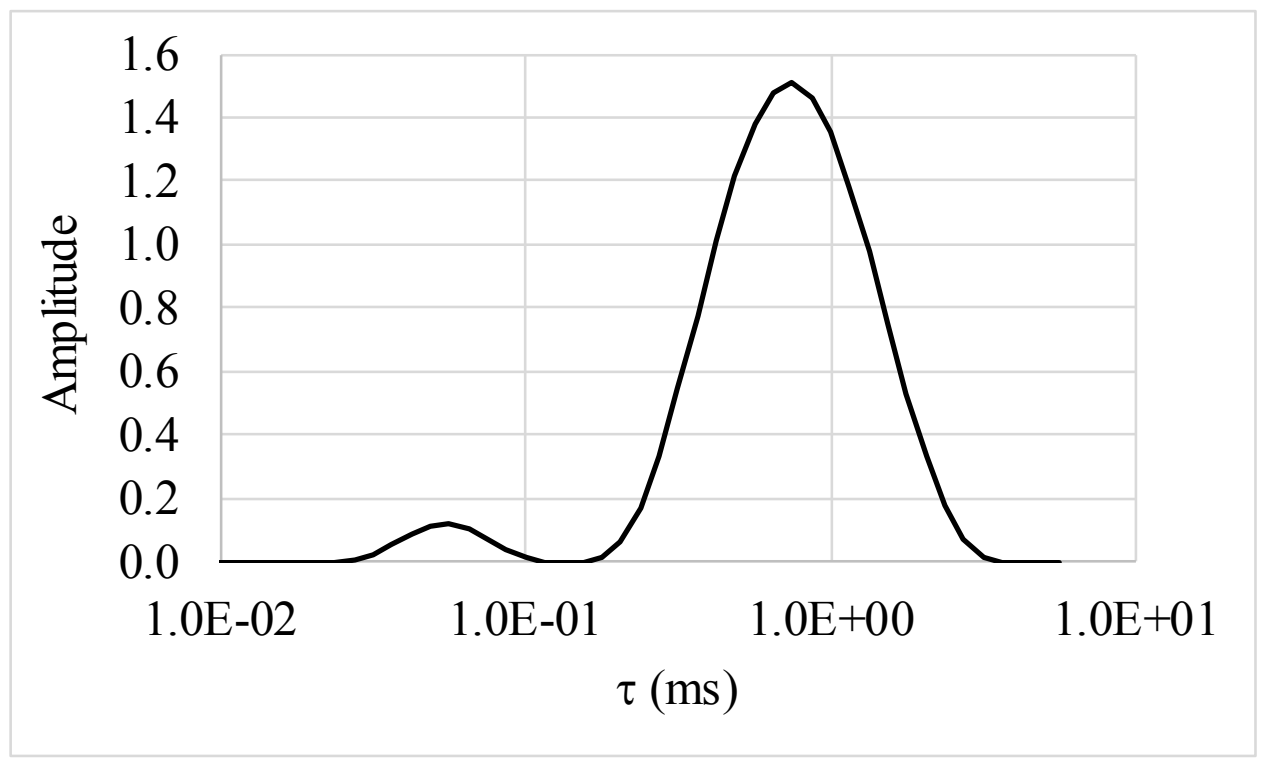

Figure S12. Intensity-weighted distribution of relaxation times in DLS at scattering angle $\theta=90^{\circ}$ for DAN- $\mathrm{U}_{2}-\mathrm{PHEA}$ at $\mathrm{C}=10^{-4} \mathrm{~mol} / \mathrm{L}$ in a water $/ \mathrm{DMSO}(99 / 1)$ mixture. 
CryoTEM image (Figure S14b) and SLS measurement (Figure S13) indicate that DAN$\mathrm{U}_{2}$-PHEA self-assembles into spherical micelles in water/DMSO.

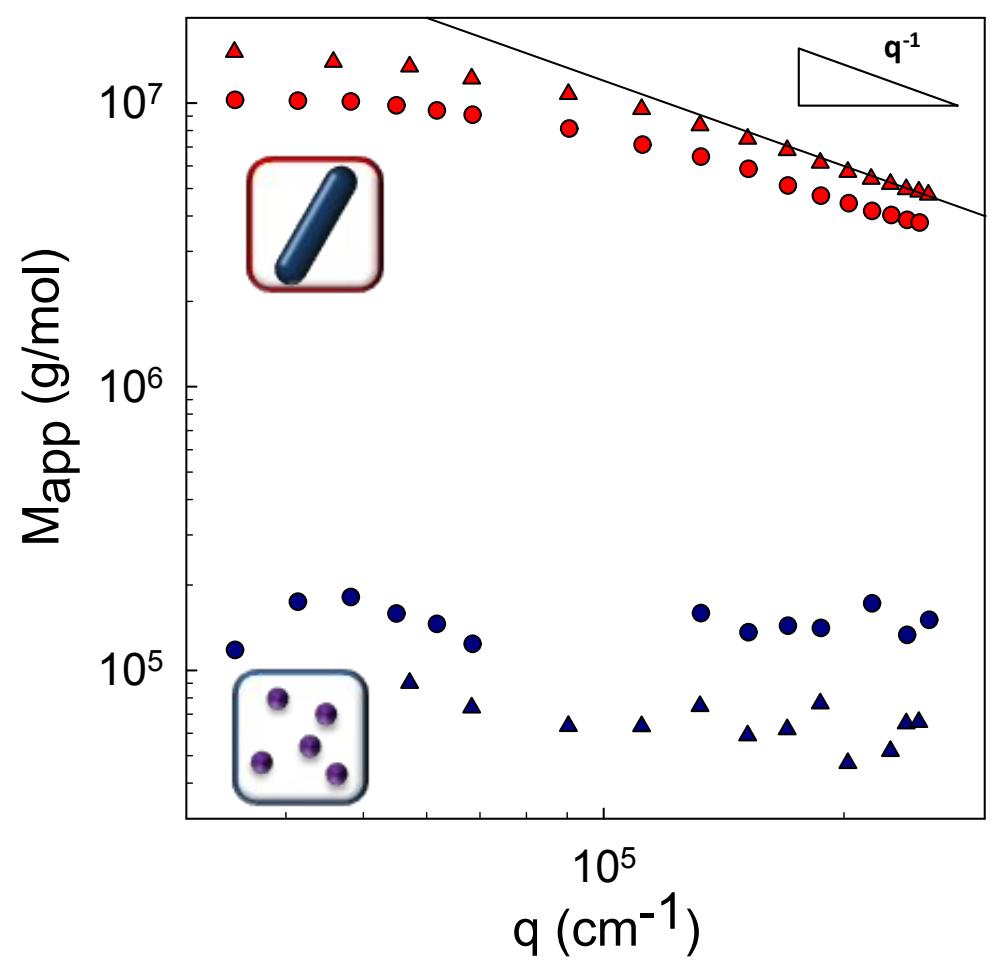

Figure S13. SLS data: wave vector (q) dependency of the apparent molar mass of DAN$\mathrm{U}_{2}$-PHEA at $\mathrm{C}=10^{-4} \mathrm{~mol} / \mathrm{L}$ (blue symbols), PEO-NDI- $\mathrm{U}_{2}$ at $\mathrm{C}=10^{-4} \mathrm{~mol} / \mathrm{L}$ (red symbols) in a water/DMSO (99/1) mixture (triangles) and in a water/DMSO (9/1) mixture (circles) 
Table S2. Apparent average molar mass $\left(\mathrm{M}_{\mathrm{app}}\right)$ and aggregation number $\left(\mathrm{N}_{\mathrm{agg}}\right)$ of the selfassemblies in water/DMSO (99/1) and in water/DMSO (9/1)

\begin{tabular}{|c|c|c|c|c|c|c|}
\cline { 2 - 7 } \multicolumn{1}{c|}{} & \multicolumn{3}{c|}{ Water/DMSO 99/1 } & \multicolumn{3}{c|}{ Water/DMSO 9/1 } \\
\cline { 2 - 7 } & $\mathrm{M}_{\text {app }}$ & $\mathrm{N}_{\text {agg }}$ & $\mathrm{R}_{\mathrm{h}}$ & $\mathrm{M}_{\text {app }}$ & & $\mathrm{R}_{\mathrm{h}}$ \\
\hline PEO-NDI-U & $1.5 \times 10^{7}$ & 6000 & 60 & $1 \times 10^{7}$ & 4000 & 65 \\
\hline & & & $(\mathrm{nm})$ & $(\mathrm{g} / \mathrm{mol})$ & & $(\mathrm{nm})$ \\
\hline DAN-U $_{2}$-PHEA & 70000 & 12 & 4 & & 24 & 8 \\
\hline
\end{tabular}

a Values determined for the fast mode. Note that the amplitude of this fast mode was small $(\sim 4-5 \%)$ compared to that of spurious scatterers so that the error on the determination of $M_{a p p}$ and $R_{\text {happ }}$ is quite large. 

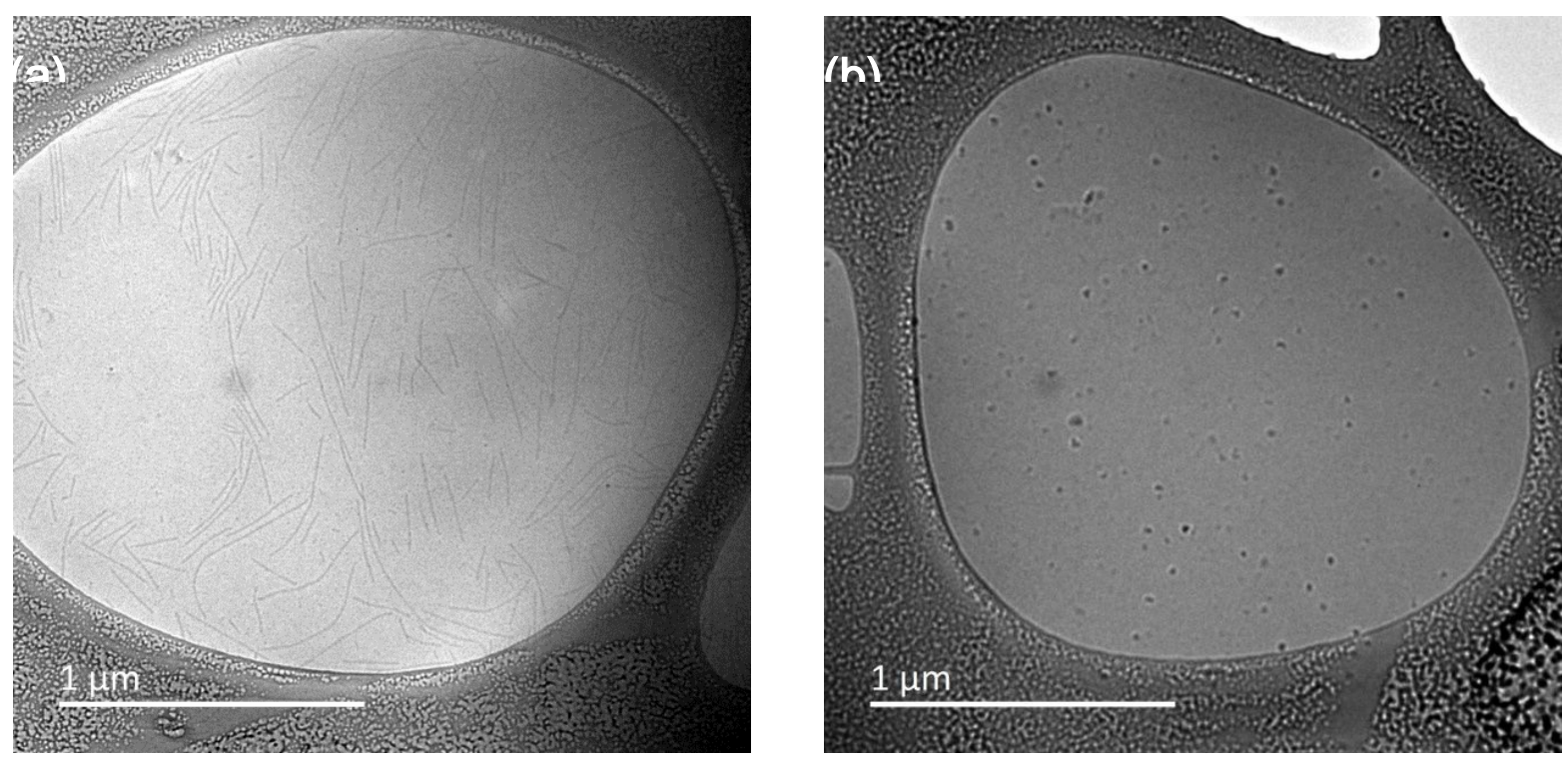

Figure S14. CryoTEM in water/DMSO (99/1) of (a) PEO-NDI- $\mathrm{U}_{2}$ at $\mathrm{C}=1.3 \mathrm{~g} / \mathrm{L}\left(0.5 \times 10^{-3}\right.$ $\mathrm{mol} / \mathrm{L})$ and $(\mathrm{b})$ DAN $-\mathrm{U}_{2}-\mathrm{PHEA}$ at $\mathrm{C}=3.1 \mathrm{~g} / \mathrm{L}\left(0.5 \times 10^{-3} \mathrm{~mol} / \mathrm{L}\right)$. 


\section{Fluorescence measurements}

Fluorescence excitation and emission spectra are shown on Figure S15. Only DAN-U $\mathbf{U}_{2}$

PHEA exhibits significant fluorescence; PEO-NDI- $\mathrm{U}_{2}$ is barely fluorescent. Unfortunately, both pre-mixing and post-mixing solutions showed similar reduction of fluorescence intensity (both in excitation and emission). It was thus concluded that PEO-NDI- $\mathrm{U}_{2}$ acted as a quencher of DAN- $\mathrm{U}_{2}$-PHEA luminescence no matter whether it is co-associated or not with this latter. Although post-mixture and pre-mixture routes gave slightly different fluorescence spectra, no clear conclusion about the formation (or not) of the charge transfer complex could be drawn from these measurements.
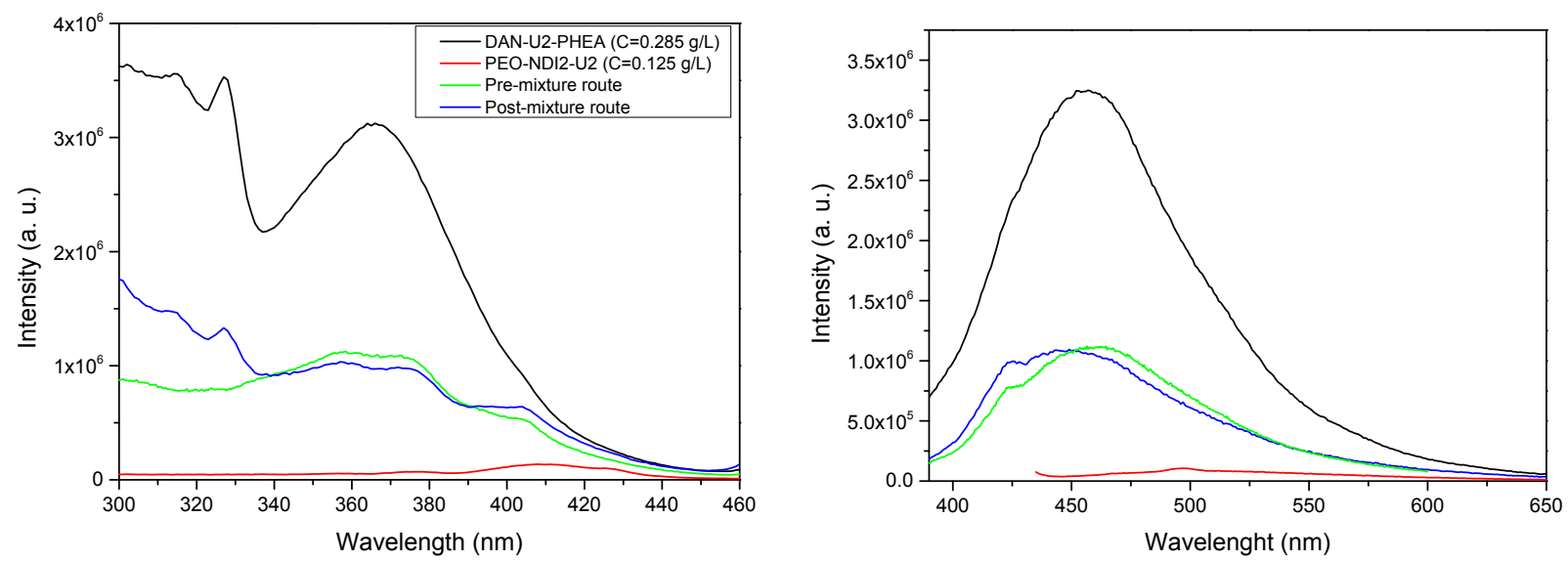
Figure S15. Fluorescence excitation $\left(\lambda_{\mathrm{em}}=470 \mathrm{~nm}\right)($ left $)$ and emission $\left(\lambda_{\mathrm{exc}}=370 \mathrm{~nm}\right)$

(right) spectra of DAN-U $U_{2}$-PHEA (black; $C=5 \times 10^{-5}$ mol. $^{-1}$ ), PEO-NDI- $U_{2}$ (red; $C=5 \times 10^{-5}$ mol.I-1 $\left.{ }^{-1}\right)$, DAN-U ${ }_{2}-$ PHEA + PEO-NDI- $U_{2}$ pre-mixture route (green) and post-mixture route (blue) at the same concentration.

\section{Evidence for no co-assembly with the post-mixing method}

Solutions containing equimolar amounts of DAN- $\mathrm{U}_{2}$-PHEA and PEO-NDI- $\mathrm{U}_{2}$ were prepared following the post-mixing method and their behavior was compared to that of reference solutions containing only one polymer at the same individual concentration as in the mixture.

5.1. UV-Visible absorption spectroscopy

UV-Visible absorption spectroscopy (Figure S16a) did not reveal any absorption band at $\lambda=550 \mathrm{~nm}$ indicating that post-mixing $\mathrm{DAN}-\mathrm{U}_{2}-\mathrm{PHEA}$ and PEO-NDI- $\mathrm{U}_{2}$ solution did not lead to the formation of the charge transfer complex. 


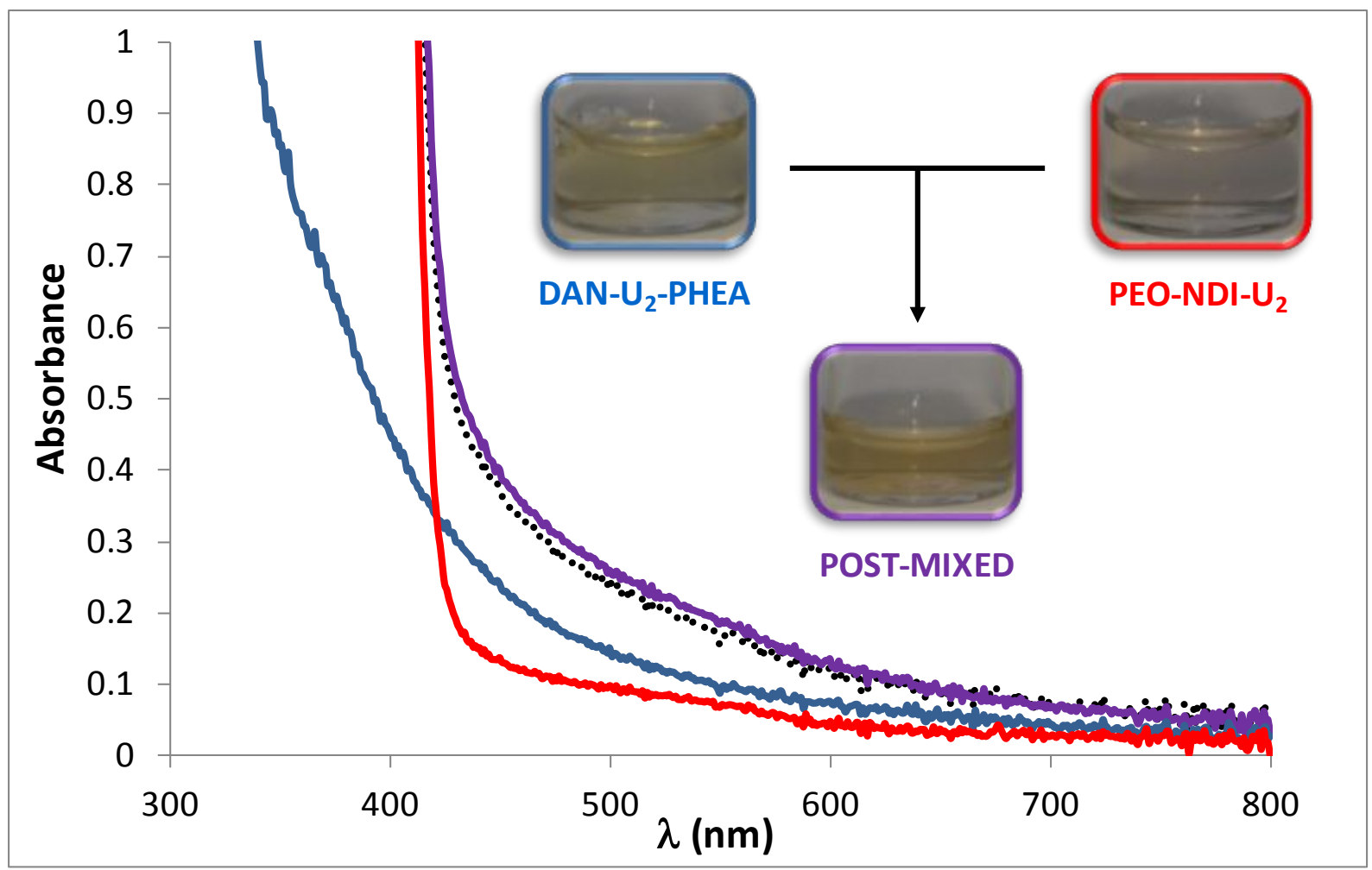

Figure S16. UV-visible spectra of DAN- $\mathrm{U}_{2}$-PHEA at $\mathrm{C}=10^{-3} \mathrm{~mol} / \mathrm{L}$ (blue), PEO-NDI- $\mathrm{U}_{2}$ at $\mathrm{C}=10^{-3} \mathrm{~mol} / \mathrm{L}$ (red) and the equimolar mixture of DAN- $\mathrm{U}_{2}-\mathrm{PHEA}$ and PEO-NDI- $\mathrm{U}_{2}$ (purple) in water $\left(\mathrm{C}_{\text {DAN-U2-PHEA }}=\mathrm{C}_{\text {PEO-NDI-U2 }}=10^{-3} \mathrm{~mol} \cdot \mathrm{L}^{-1}\right)$. The black dashed line represents the mathematical sum of DAN- $\mathrm{U}_{2}-\mathrm{PHEA}$ and PEO-NDI- $\mathrm{U}_{2}$ spectra. (insert)

Pictures of the corresponding solutions.

5.2. Light scattering analysis 
The mathematical sum of the raw scattered light intensity of individual $D A N-U_{2}-$ PHEA and PEO-NDI- $\mathrm{U}_{2}$ solutions was compared to that of the polymer mixture prepared in water following the post-mixing method. Figure S17 shows that within experimental uncertainty the light intensity scattered by the mixture is equal to the sum of the intensities scattered by individual solutions. This indicates that the objects present in the polymers mixtures remained the same as when they were in individual solutions, confirming the absence of co-assembly of DAN- $U_{2}$-PHEA and PEO-NDI- $U_{2}$ with the post-mixing method.

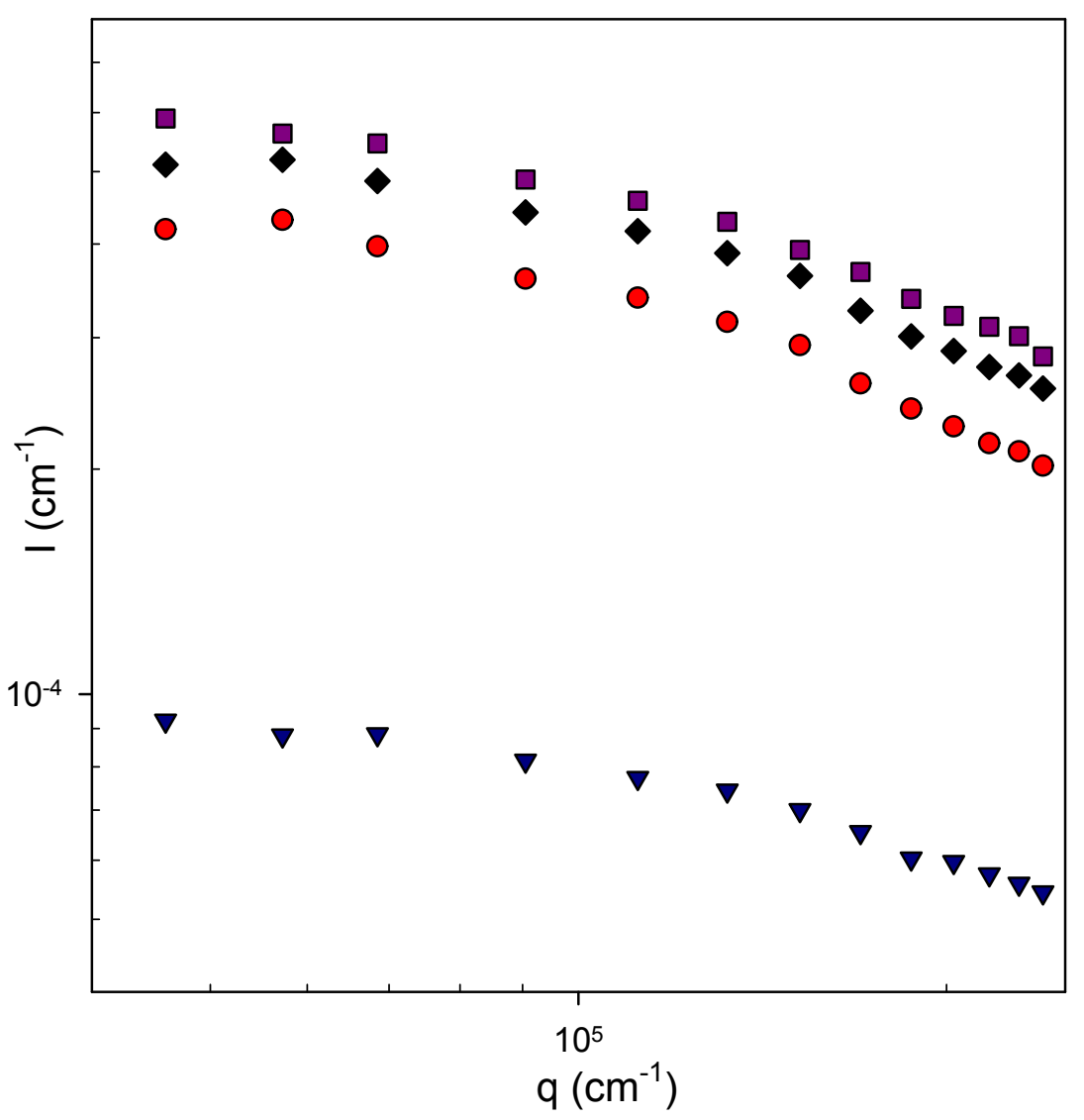


Figure S17. Wave vector (q) dependency of the raw scattered light intensity of DAN- $U_{2}$ -

PHEA at $C=8.6 \times 10^{-5} \mathrm{~mol} / \mathrm{L}$ (triangles), $\mathrm{PEO}-\mathrm{NDI}-\mathrm{U}_{2}$ at $\mathrm{C}=8.6 \times 10^{-5} \mathrm{~mol} / \mathrm{L}$ (circles) and the equimolar mixture of DAN- $\mathrm{U}_{2}$-PHEA and PEO-NDI- $\mathrm{U}_{2}$ (squares) in a water $\left(\mathrm{C}_{\text {tot }}=\right.$ $\left.1.72 \times 10^{-4} \mathrm{~mol} . \mathrm{L}^{-1}\right)$ prepared following the post-mixing method. The diamonds represent the mathematical sum of intensities scattered by DAN- $\mathrm{U}_{2}$-PHEA and PEO-NDI- $\mathrm{U}_{2}$. 
6. Evidence for co-assembly with the pre-mixing method and characterization of the co-

assemblies

\subsection{Light scattering analysis}

Figure S18 shows the wave vector dependency of the raw scattered light intensity for both individual building block solutions and their mixture obtained using the pre-mixing

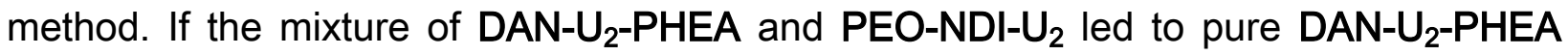
spheres and pure PEO-NDI- $\mathrm{U}_{2}$ cylinders with no co-assembly, the light intensity scattered by this mixture should be equal to the sum of the intensities of individual solutions. Figure S18 clearly shows that the intensity scattered by the pre-mixed solution is strongly different from the sum of the intensities scattered by the individual polymers solutions. This indicates that co-assembly of both polymers occurred at least partly. 


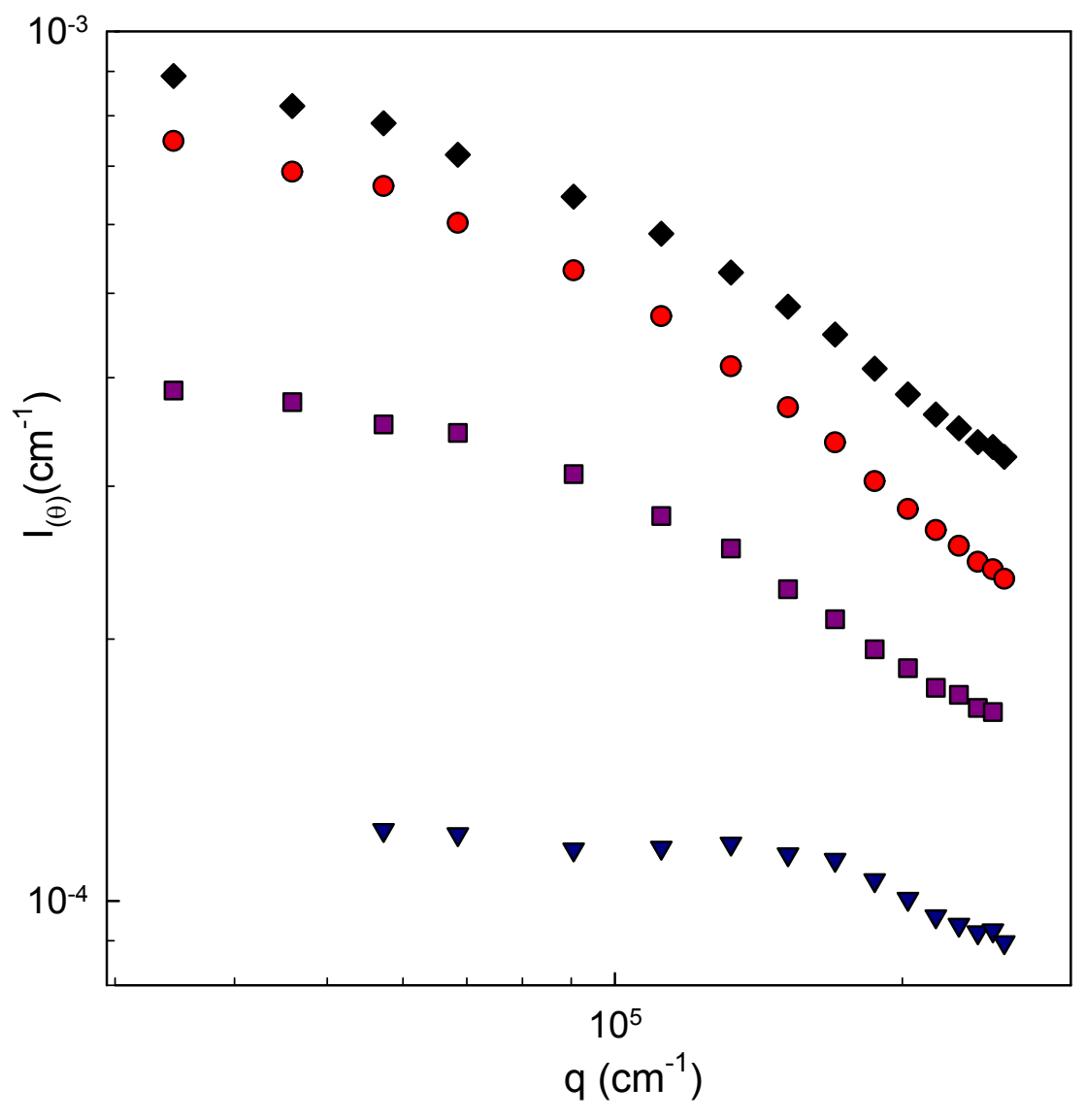

Figure S18. Wave vector(q) dependency of the raw scattered light intensity of DAN- $\mathbf{U}_{2}$ -

PHEA at $C=10^{-4} \mathrm{~mol} / \mathrm{L}$ (triangles), PEO-NDI- $\mathrm{U}_{2}$ at $\mathrm{C}=10^{-4} \mathrm{~mol} / \mathrm{L}$ (circles) and the equimolar mixture of DAN-U $\mathrm{U}_{2}$-PHEA and PEO-NDI-U ${ }_{2}$ (squares) in a water/DMSO (9/1) mixture $\left(\mathrm{C}_{\text {tot }}=2 \times 10^{-4} \mathrm{~mol} . \mathrm{L}^{-1}\right)$ obtained by pre-mixing. The diamonds represent the mathematical sum of intensities scattered by DAN- $\mathrm{U}_{2}-\mathrm{PHEA}$ and PEO-NDI- $\mathrm{U}_{2}$. (The solid line has a slope of -1$)$. 
6.2. Cryo-TEM

From the cryoTEM experiments conducted on pure PEO-NDI- $\mathrm{U}_{2}$ (Figure S14a), pure

DAN- $U_{2}-$ PHEA (Figure S14b), the post-mixed (Figures 2a and S19a) and the pre-mixed

(Figures $2 \mathrm{~b}$ and $19 \mathrm{~b}$ ) PEO-NDI- $\mathrm{U}_{2} / \mathrm{DAN}_{2}-\mathrm{UHEA}$ samples, all particles on several pictures (about 100-300 particles) were manually counted and their size was measured.

The corresponding distribution histograms are represented on Figures S19c-d. 


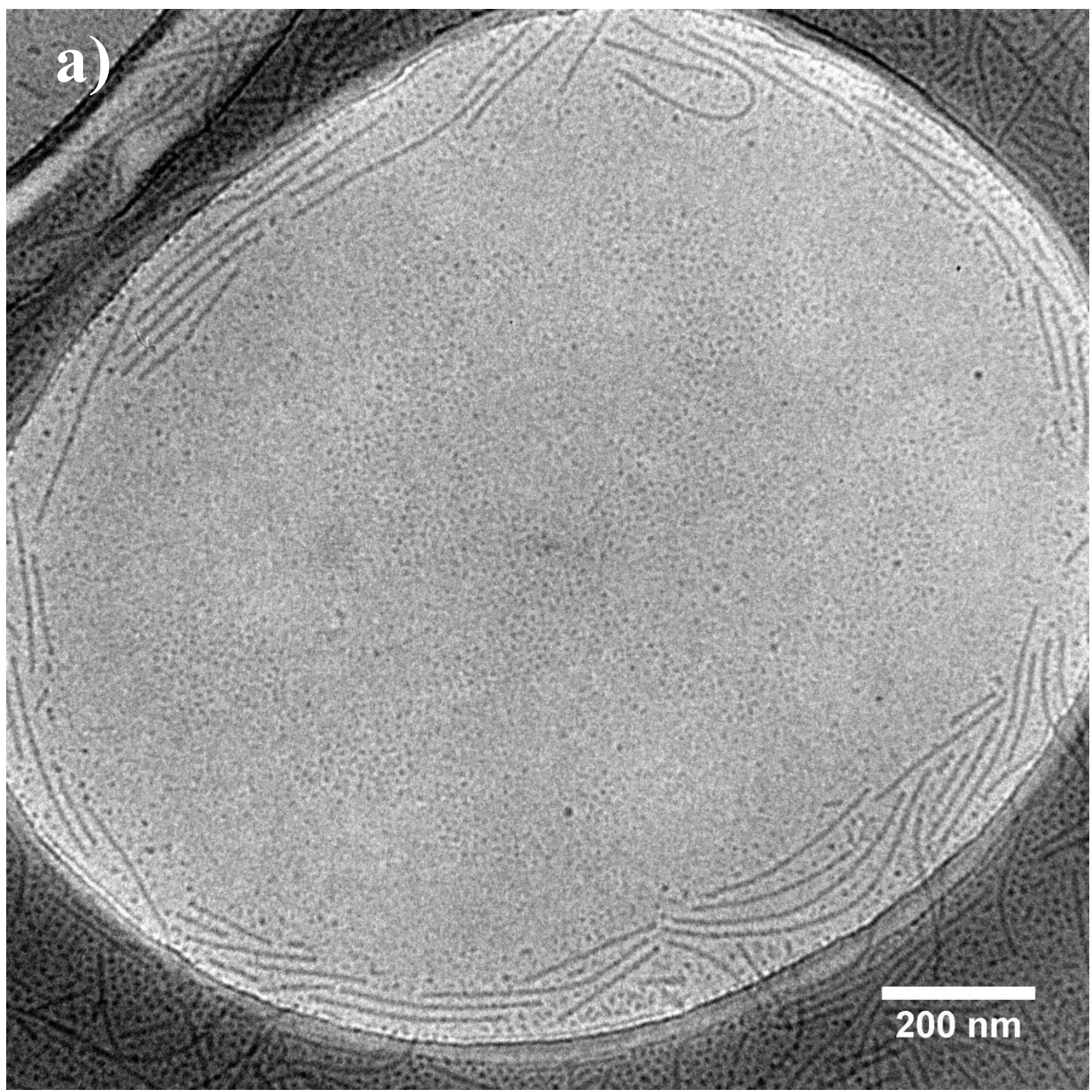




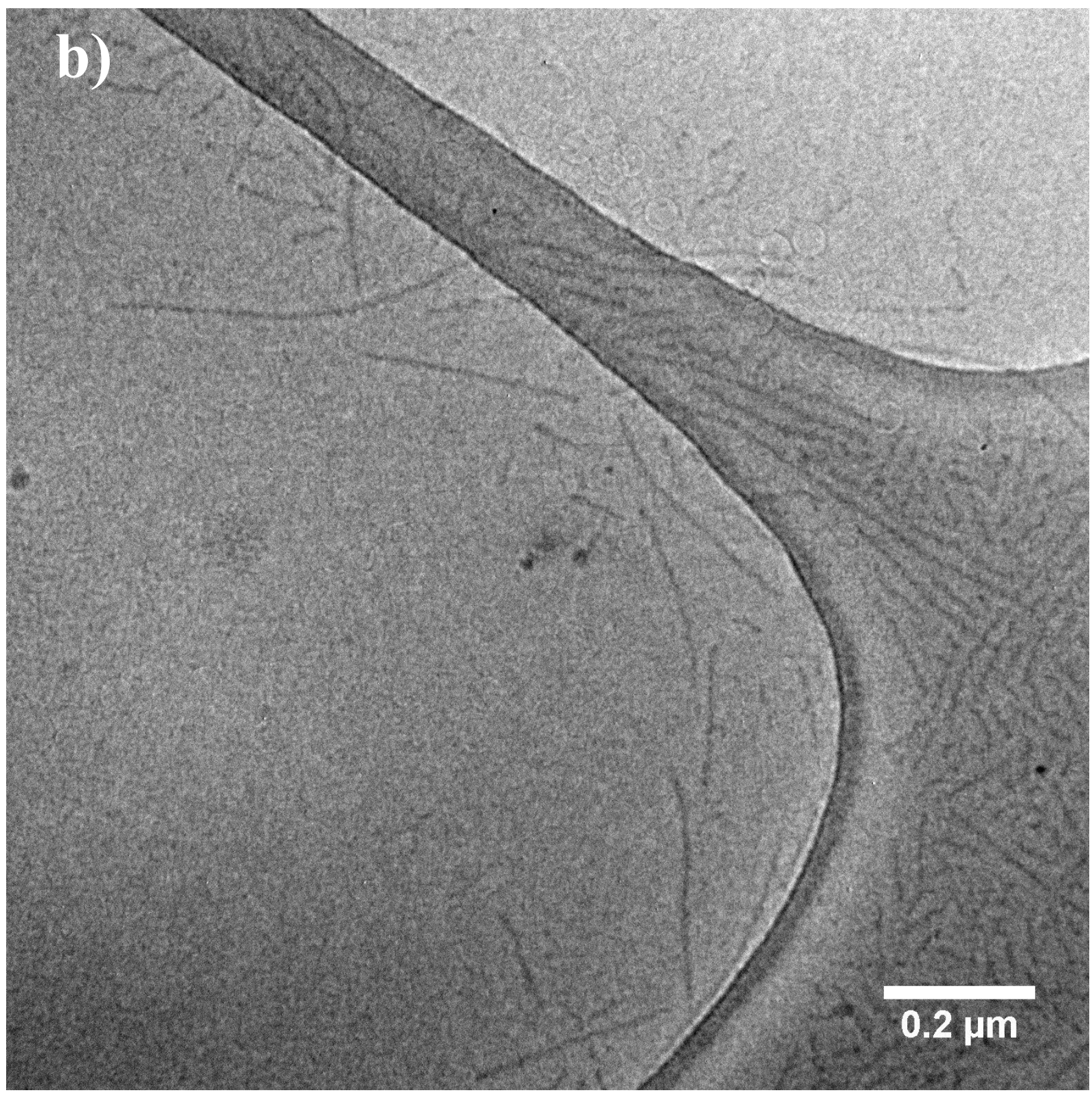



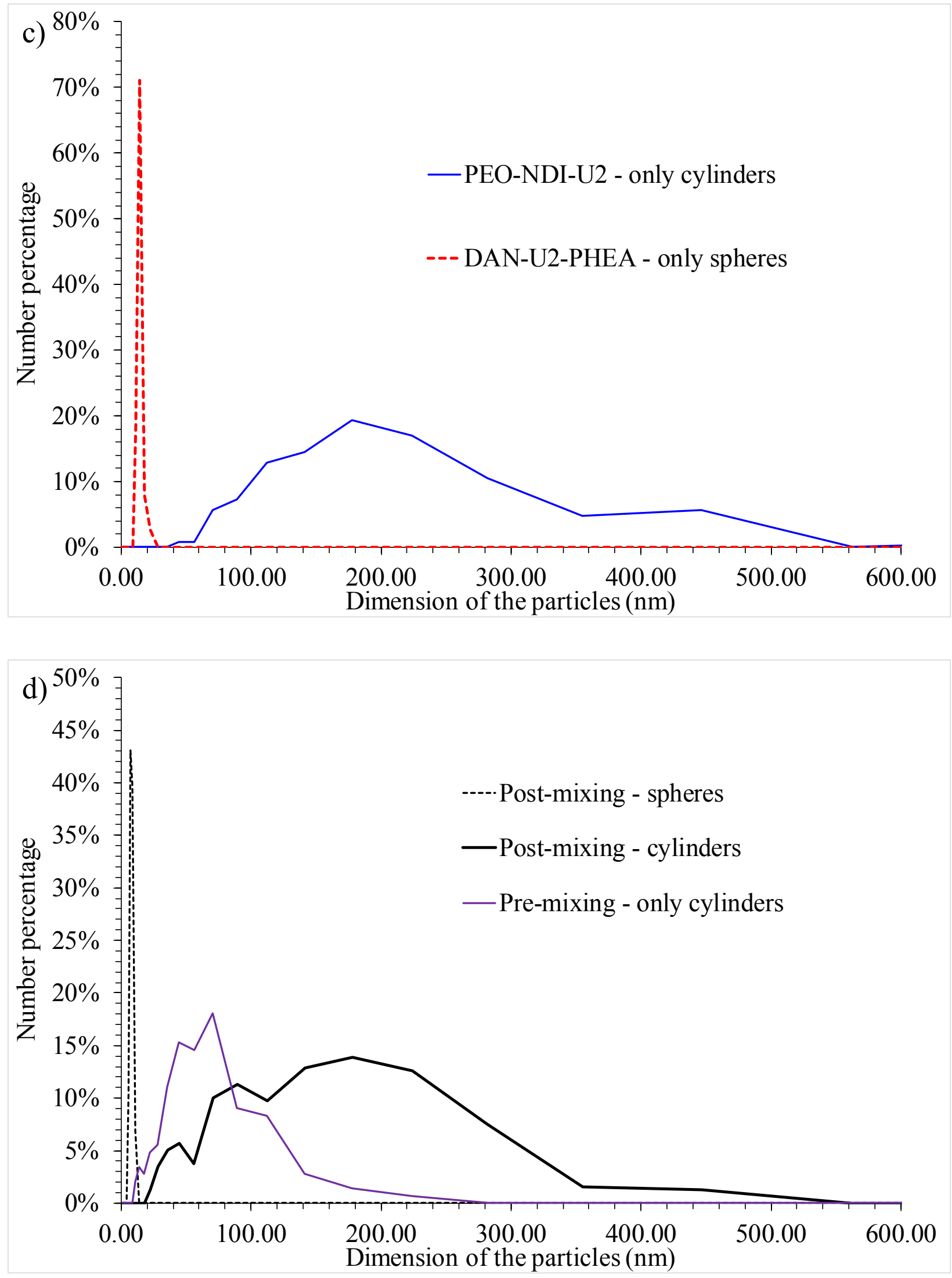
Figure S19. CryoTEM images of an equimolar mixture of DAN-U ${ }_{2}-\mathrm{PHEA}$ and PEO-NDI$U_{2}$ prepared either following a) the post-mixing route $\left(C=5.3 \times 10^{-4} \mathrm{~mol} . \mathrm{L}^{-1}\right.$ of each polymer in $\left.\mathrm{H}_{2} \mathrm{O}\right)$ revealing co-existence of spheres and cylinders, or $\left.\mathbf{b}\right)$ the pre-mixing route $(\mathrm{C}=$ $5.3 \times 10^{-4}$ mol.L-1 of each polymer in DMSO- $\left.\mathrm{d}_{6} / \mathrm{D}_{2} \mathrm{O}=1 / 9\right)$ showing only cylinders. Note that the images here are purposefully different from that shown in Figure 2 for representativity but it was obtained on the same sample. c) Size distribution histogram showing the length of the cylinders (spheres were not observed) for PEO-NDI- $U_{2}(C=$ $5.2 \times 10^{-4} \mathrm{~mol}^{-L^{-1}}$ in DMSO- $\mathrm{d}_{6} / \mathrm{D}_{2} \mathrm{O}=1 / 99$ ) and the diameter of the spheres (cylinders were not observed $)$ for DAN- $U_{2}$-PHEA $\left(C=5.4 \times 10^{-4}\right.$ mol.L $^{-1}$ in DMSO- $\left.d_{6} / D_{2} \mathrm{O}=1 / 99\right)$. d) Size distribution histogram showing the length of the cylinders and the diameter of the spheres for the post-mixing route $\left(\mathrm{C}=5.3 \times 10^{-4}\right.$ mol. $\mathrm{L}^{-1}$ of each polymer in $\left.\mathrm{H}_{2} \mathrm{O}\right)$ or the length of the cylinders (no spheres are present) for the pre-mixing route $\left(C=5.3 \times 10^{-4}\right.$ mol. $\mathrm{L}^{-1}$ of each polymer in DMSO- $d_{6} / D_{2} \mathrm{O}=1 / 9$ ). c) and d) were obtained by manually counting $100-300$ particles. 


\subsection{PFG NMR experiments}

The Stejskal-Tanner plot measured for the $-\mathrm{O}-\mathrm{CH}_{2}$ - protons of the PEO chains from PEO-NDI- $\mathrm{U}_{2}(\mathrm{O})$ and the $\left(-\mathrm{O}-\mathrm{CH}_{2}-\mathrm{CH}_{2}-\mathrm{OH}\right)$ protons of the PHEA chains from DAN- $\mathrm{U}_{2}$ PHEA $(\bullet)$ is reported in Figure S20. These experiments were performed on a pre-mixed sample, prepared with a $D_{2} \mathrm{O} / \mathrm{DMSO}-\mathrm{d}_{6}(9 / 1)$ mixture. As expected, the NMR signal attenuation $A / A_{0}$ determined for the $\left(-\mathrm{O}-\mathrm{CH}_{2}-\mathrm{CH}_{2}-\mathrm{OH}\right)$ protons of the PHEA chains is found to superimpose with the one obtained for the PHEA $\left(-\mathrm{O}-\mathrm{CH}_{2}-\mathrm{CH}_{2}-\mathrm{OH}\right)$ protons. This signal attenuation $A / A_{0}$ can essentially be described using a single-exponential component. In other words, a single diffusion component is detected for the PHEA protons, indicating that $\mathrm{DAN}-\mathrm{U}_{2}$-PHEA is involved in a single kind of assemblies, characterized by a diffusion coefficient equal to $2.8 \times 10^{-11} \mathrm{~m}^{2} \cdot \mathrm{s}^{-1}$. In contrast, the evolution of $A / A_{0}$ with the factor $\gamma^{2} \cdot g^{2} \cdot \delta^{2} \cdot(\Delta-\delta / 3)$ for the PEO chains in the pre-mixed sample significantly differs from the behavior observed for $\mathrm{DAN}-\mathrm{U}_{2}$-PHEA. More than one diffusion component is clearly detected, as shown in Figure S20. Interestingly, the fast diffusing component is shared with the one determined for the PHEA chains. However, a slow diffusing component, characterized by a diffusion coefficient of $3.7 \times 10^{-12} \mathrm{~m}^{2} \cdot \mathrm{s}^{-1}$, is 
also detected for part of the PEO chains. This feature indicates that this pre-mixed sample is schematically composed of two kinds of assemblies: a first one, involving all the PHEA chains and a fraction of the PEO chains; a second one, corresponding to larger assemblies mostly composed of PEO-NDI- $\mathrm{U}_{2}$.

The biexponential description of the NMR signal attenuation recorded for the PEO protons leads to an amplitude $A_{\mathrm{f}}$ of $64 \%$ for the fast diffusing component (and $A_{\mathrm{s}}=36 \%$ for the slow diffusing component). $A_{\mathrm{f}}\left(A_{\mathrm{s}}\right.$, respectively) may be related to the fraction $p_{\mathrm{f}}$ $\left(p_{\mathrm{s}}\right.$, respectively) of PEO-NDI- $\mathrm{U}_{2}$ involved in Janus nanocylinders (PEO-NDI- $\mathrm{U}_{2}$ selfassemblies, respectively), taking into account both $T_{1}\left({ }^{1} \mathrm{H}\right)$ and $T_{2}\left({ }^{1} \mathrm{H}\right)$ relaxation effects occurring during the pulse sequence, for both kinds of nanostructures: $\left[T_{1}\left({ }^{1} \mathrm{H}\right)\right]_{\mathrm{f}}$ and $\left[T_{2}\left({ }^{1} \mathrm{H}\right)\right]_{\mathrm{f}}$ for hybrid assemblies; $\left[T_{1}\left({ }^{1} \mathrm{H}\right)\right]_{\mathrm{s}}$ and $\left[T_{2}\left({ }^{1} \mathrm{H}\right)\right]_{\mathrm{s}}$ for PEO-NDI- $\mathrm{U}_{2}$ self-assemblies. These four relaxation times will be denoted as $T_{1 \mathrm{f}}, T_{2 \mathrm{f}}, T_{1 \mathrm{~s}}$ and $T_{2 \mathrm{~s}}$ in the following. More precisely, the ratio between $p_{\mathrm{f}}$ and $p_{\mathrm{s}}$ may be expressed as:

$$
\frac{p_{f}}{p_{s}}=\frac{A_{f}}{A_{s}} \times \frac{e^{-t_{2} / T_{2 s}}}{e^{-t_{2} / T_{2 f}}} \times \frac{e^{-t_{1} / T_{1 s}}}{e^{-t_{1} / T_{1 f}}}
$$


$t_{1}$ and $t_{2}$ corresponding to the delay of the pulse sequence involving $T_{1}\left({ }^{1} \mathrm{H}\right)$ and $T_{2}\left({ }^{1} \mathrm{H}\right)$ relaxation, respectively. In the present case, $t_{1}$ corresponds to the diffusion time $\Delta$ while $t_{2}=2 \delta, \delta$ being the gradient pulse length. Inversion-recovery measurements were performed to determine the $T_{1}\left({ }^{1} \mathrm{H}\right)$ relaxation functions for the protons of both PHEA and PEO components in the pre-mixed sample. For the PEO protons, a mono-exponential $T_{1}\left({ }^{1} \mathrm{H}\right)$ decay was observed, which indicates that $\left[T_{1}\left({ }^{1} \mathrm{H}\right)\right]_{\mathrm{s}}$ and $\left[T_{1}\left({ }^{1} \mathrm{H}\right)\right]_{\mathrm{f}}$ are either equal or, if not, so close that their difference could not be detected experimentally. Under these conditions, Equation S1 may be simplified:

$$
\frac{p_{f}}{p_{s}}=\frac{A_{f}}{A_{s}} \times \frac{e^{-2 t_{2} / T_{2 s}}}{e^{-{ }^{2 t_{2}} / T_{2 f}}}
$$

The $T_{2}\left({ }^{1} \mathrm{H}\right)$ relaxation signals were also determined for the protons of both PEO and PHEA components in the pre-mixed sample (Figure 6 of the manuscript). The decays related to the PEO chains in the Janus nanocylinders and in the PEO-NDI- $\mathrm{U}_{2}$ selfassemblies present in the mixture cannot be, obviously, discarded. Nevertheless, the $T_{2}\left({ }^{1} \mathrm{H}\right)$ decay measured for the PEO chains in the mixture (composed of both Janus nanocylinders and PEO-NDI- $\mathrm{U}_{2}$ self-assemblies) and the one obtained on neat PEO-NDI- 
$\mathrm{U}_{2}$ cannot be superimposed, but are rather close. This result suggests that the $T_{2}\left({ }^{1} \mathrm{H}\right)$ relaxation behavior for the PEO chains involved in Janus nanocylinders and in PEO-NDI$\mathrm{U}_{2}$ self-assemblies should be rather similar. By the way, this feature is consistent with the fact that the PEO chains should experience a very close segmental dynamics in both kinds of nanostructures. Besides, for the PFG-NMR experiments reported in Figure S20, the value of $2 \cdot t_{2}$ in Equation $\mathrm{S} 2$ is equal to $2 \mathrm{~ms}$. At $\mathrm{t}=2 \mathrm{~ms}$, the signal attenuation due to $T_{2}\left({ }^{1} \mathrm{H}\right)$ relaxation amounts to $2.4 \%$ for the PEO chains in the pre-mixed sample and $3.4 \%$ for PEO-NDI- $U_{2}$ self-assemblies (see Figure 6 of the manuscript). Based on these considerations related to the $T_{2}\left({ }^{1} \mathrm{H}\right)$ relaxation effects in Equation S2, one may conclude that in the present case, the ratio $p_{\mathrm{f}} / p_{\mathrm{s}}$ should be very close to $A_{\mathrm{f}} / A_{\mathrm{s}}$, deduced from the amplitude of the diffusion components observed for PEO in Figure S20. 


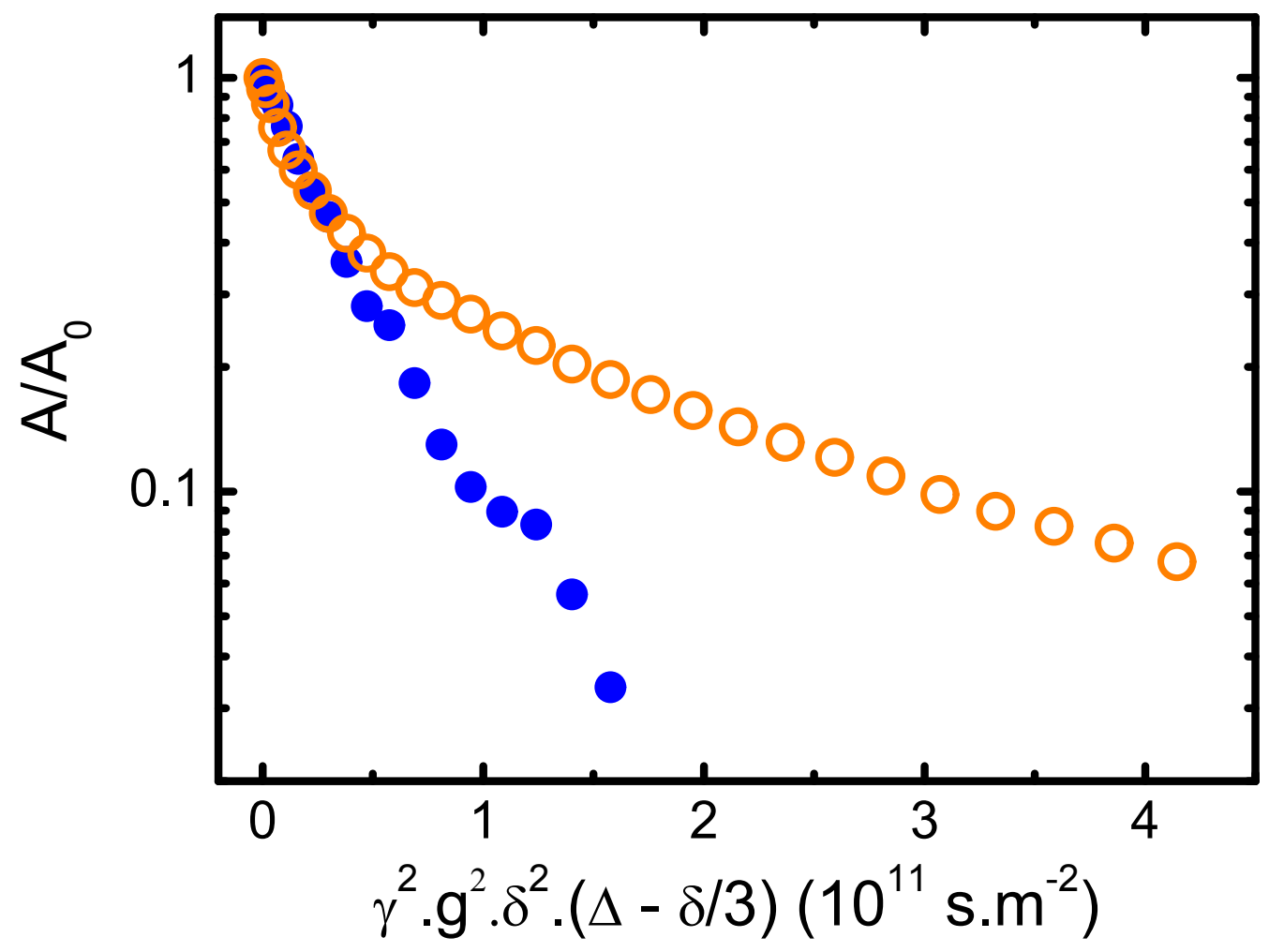

Figure S20. Echo attenuation $A / A_{0}$ as a function of $\gamma^{2} \cdot g^{2} \cdot \delta^{2} \cdot(\Delta-\delta / 3)$ for the PEO protons from PEO-NDI- $\mathrm{U}_{2}(\mathrm{O})$ and for the PHEA protons $\left(-\mathrm{O}-\mathrm{C}_{2}-\mathrm{CH}_{2}-\mathrm{OH}\right)$ from DAN- $\mathrm{U}_{2}-\mathrm{PHEA}$ $(\bullet)$ in an equimolar mixture of both components in $\mathrm{D}_{2} \mathrm{O} / \mathrm{DMSO}-\mathrm{d}_{6}(9 / 1)$ (pre-mixed sample). $A_{0}$ denotes the area under the NMR peak considered, at the weakest gradient strength value $(g=15.3 \mathrm{G} / \mathrm{cm})$. The concentration of each polymer is set to $C=5.3 \times 10^{-4}$ mol. $\mathrm{L}^{-1}$. The measurements were performed at $23^{\circ} \mathrm{C}$. 


\subsection{Determination of the shape of the co-assemblies}

In order to probe if the pre-mixed sample could contain only pure PEO-NDI- $\mathbf{U}_{2}$ nanocylinders mixed with PEO-NDI- $\mathrm{U}_{2} / \mathrm{DAN}-\mathrm{U}_{2}$-PHEA co-assemblies that were too small to be visible in cryoTEM, the SANS scattered intensity of the pre-mixed sample was compared to that of PEO-NDI- $U_{2}$ plus hypothetical small spherical aggregates of coassembled PEO-NDI- $\mathrm{U}_{2} /$ DAN- $\mathrm{U}_{2}-\mathrm{PHEA}$ with a radius of $5 \mathrm{~nm}$. The amount of pure PEONDI- $U_{2}$ in the pre-mixed solutions was determined to be $\sim 36 \%$ by PFG NMR experiments (see above). The intensity scattered by $40 \%$ of pure PEO-NDI- $\mathrm{U}_{2}$ nanocylinders in the pre-mixed solution (corresponding to a concentration of $0.13 \mathrm{~g} / \mathrm{L}$ ) was determined for safety. The latter was deduced from the scattered intensity measured at $1 \mathrm{~g} / \mathrm{L}$ assuming no concentration effect (dilute regime). The intensity scattered by the hypothetical spherical aggregates of PEO-NDI- $\mathrm{U}_{2}$ and $\mathrm{DAN}-\mathrm{U}_{2}$-PHEA was calculated based on a model of spherical aggregates with a contrast $\mathrm{K}_{\text {SANS }}=2.19 \times 10^{-3} \mathrm{~mol} \cdot \mathrm{cm}^{2} \cdot \mathrm{g}^{-2}$ (see "Combining SLS and SANS data" section in 1.2 of the $\mathrm{SI}$ ), and their concentration (C $\mathrm{C}_{\text {PEO- }}$ NDI-U2 corresponded to $60 \%$ of the concentration of this molecule in the pre-mixed sample $\left.=0.20 \mathrm{~g} / \mathrm{L}, \mathrm{C}_{\text {DAN-U2-PHEA }}=0.74 \mathrm{~g} / \mathrm{L}\right)$. Figure $\mathrm{S} 21$ shows that the scattered intensity and its 
$\mathrm{q}^{-1}$-dependency at low $\mathrm{q}$ cannot be accounted for simultaneously by this simulation, whatever the proportion and radius of the hypothetical population of spheres. The only possibility to quantitatively match the SANS data would be to consider a cylinder concentration much higher than the one due to the $36 \%$ of pure PEO-NDI- $\mathrm{U}_{2}$ cylinders determined by the PFG experiments. It can therefore be deduced that the PEO-NDI$\mathrm{U}_{2} /$ DAN-U $\mathrm{U}_{2}$-PHEA pre-mixture contained $\sim 36 \%$ of self-sorted PEO-NDI- $\mathrm{U}_{2}$ nanocylinders as well as significantly aggregated co-assemblies with a cylindrical shape that accounts for the experimental scattering profile. 


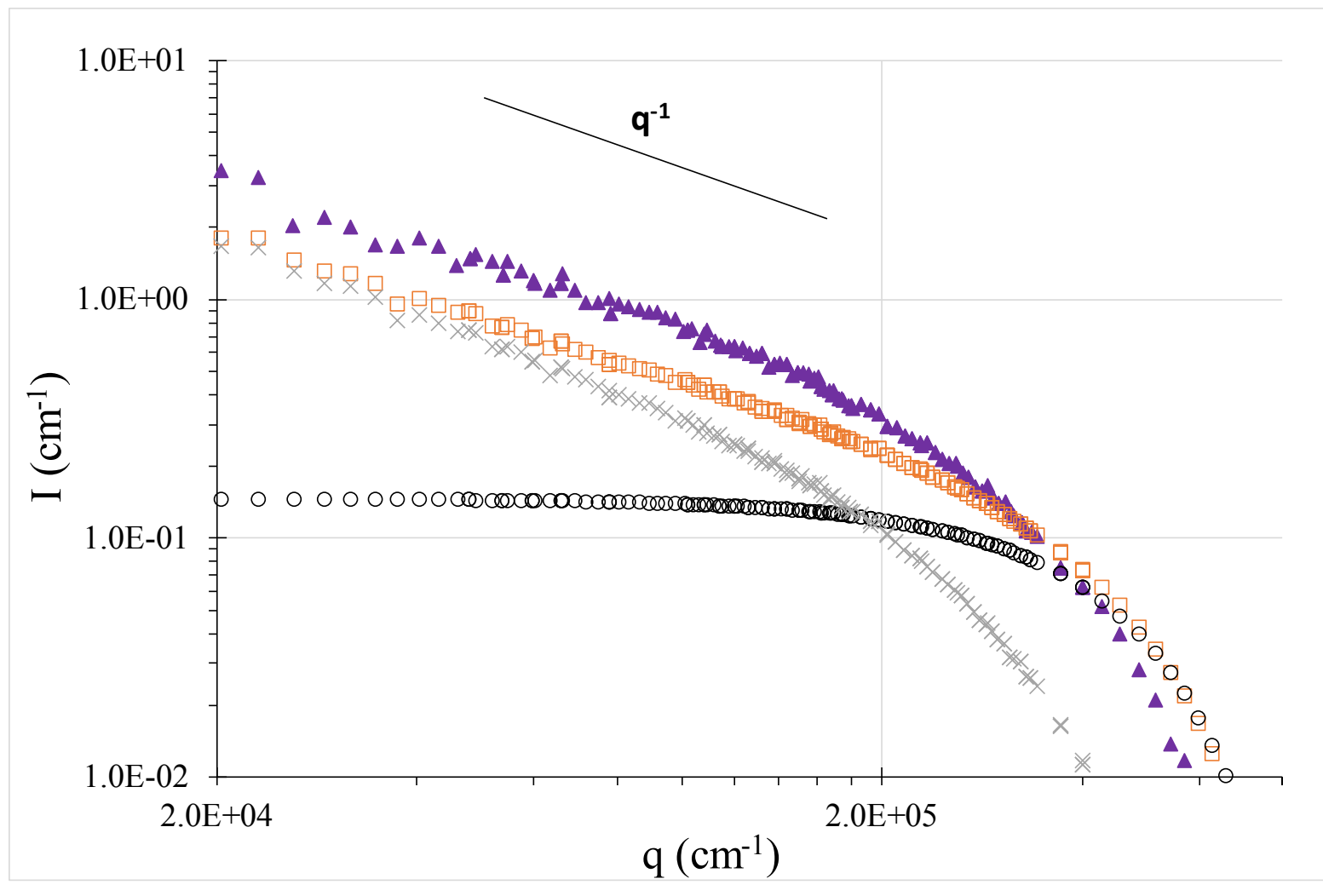

Figure S21. Evolution of the scattering intensity (I) as a function of the scattering wave vector (q) obtained by SANS for the pre-mixed sample of PEO-NDI- $\mathrm{U}_{2}(0.33 \mathrm{~g} / \mathrm{L})$ and DAN- $\mathrm{U}_{2}$-PHEA $(0.74 \mathrm{~g} / \mathrm{L})$ in $\mathrm{D}_{2} \mathrm{O} / \mathrm{DMSO}^{-} \mathrm{d}_{6}(99 / 1)(\boldsymbol{\Delta})$. The data are compared with an hypothetical model corresponding to the contribution of pure PEO-NDI- $\mathrm{U}_{2}$ nanocylinders at $0.13 \mathrm{~g} / \mathrm{L}\left(40 \%\right.$ of the total amount of PEO-NDI- $\mathrm{U}_{2}$ in the pre-mixed sample) mixed with spherical aggregates of $5 \mathrm{~nm}$ containing a PEO-NDI- $\mathrm{U}_{2} / \mathrm{DAN} \mathrm{U}_{2}-\mathrm{PHEA}$ ratio of $0.6: 1$ and exhibiting a $\mathrm{DP}_{\mathrm{n}}=20(\square)$. The respective scattering curves of $40 \%$ of PEO-NDI-U $\mathrm{U}_{2}$ 
nanocylinders $(x)$ and of the small spherical aggregates $(O)$ are also represented. The straight line follows a $\mathrm{q}^{-1}$ dependency of the scattered intensity.

6.5. Determination of the radius of the cylinders and of their molecular weight per $\mathrm{nm}$

The combined SLS and SANS data obtained for equimolar solutions of PEO-NDI- $\mathbf{U}_{2}$ and DAN- $U_{2}$-PHEA were fitted using a model of cylinders of circular cross-section with uniform contrast ${ }^{15,16}$ using the open source SASView Software (http://www.sasview.org/).

For the model of monodisperse cylinders presented in the manuscript (Figure 4) and on Figure $S 22$ with a lq $=f(q)$ representation, the adjusted parameters were the length $L$ of the cylinders, their weight average apparent molar mass $M_{a p p}$ and their cross sectional radius $r$. 


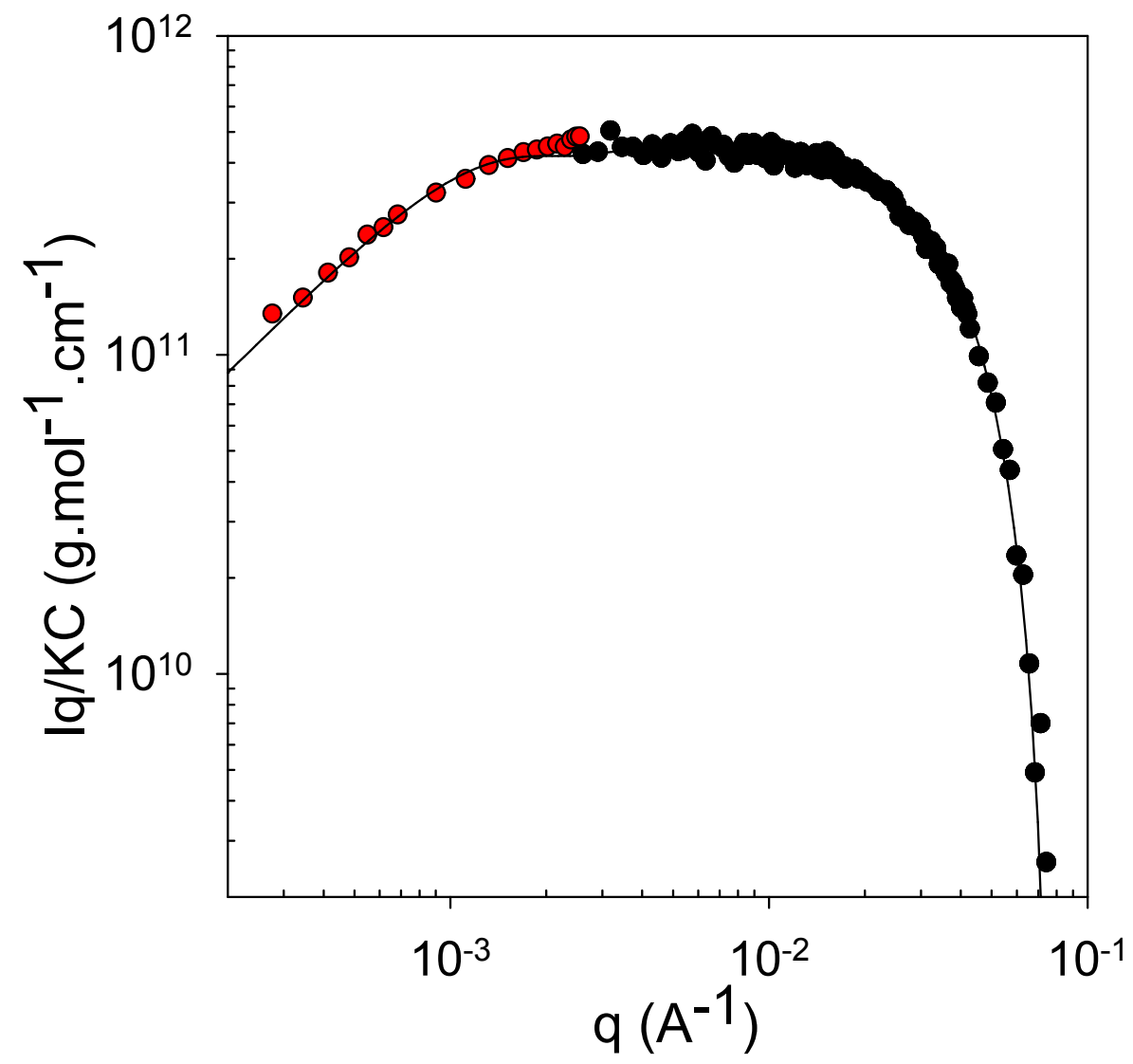

Figure S22. Evolution of I.q as a function of the scattering wave vector (q) obtained by the combination of LS $(\bullet)$ and SANS $(\bullet)$ for the equimolar mixture of PEO-NDI- $\mathrm{U}_{2}$ and DAN- $U_{2}-$ PHEA at $C_{\text {tot }}=1 \mathrm{~g} / \mathrm{L}\left(C_{\text {tot }}=2.4 \times 10^{-4}\right.$ mol.L-1 $)$ in $D_{2} \mathrm{O} /$ DMSO- $\mathrm{d}_{6}(99 / 1)$ with $(\mathrm{I} . \mathrm{q} / \mathrm{KC})_{0} \approx 4.4 \times 10^{11} \mathrm{~g} \cdot \mathrm{mol} . \mathrm{cm}^{-1}$. Same data as Figure 4 .

When the cylinders are very long, the model of homogenous cylinders used in SASView can be simplified into Equations S3-S5, valid for infinitely long cylinders. ${ }^{9,} 10$ 


$$
\begin{aligned}
& I=\frac{\pi C}{q} \cdot \mathrm{K} \cdot M_{L}\left[2 \frac{J_{1}(q r)}{q r}\right]^{2} \\
& (q I)_{q \rightarrow 0}=(q I)_{0} \exp \left(-\frac{\mathrm{r}^{2}}{4} q^{2}\right) \\
& (q I)_{0}=\pi C \cdot \mathrm{K} \cdot M_{L}
\end{aligned}
$$

Where $\mathrm{C}$ is the polymer concentration $\left(\mathrm{g} \cdot \mathrm{cm}^{-3}\right), \mathrm{M}_{\mathrm{L}}$ is the molecular weight per unit length of the cylinder $\left(\mathrm{g} \cdot \mathrm{mol}^{-1} \cdot \mathrm{cm}^{-1}\right), \mathrm{r}$ is the radius of the cross section, $\mathrm{K}$ is the contrast defined as in Equations 4 and $\mathbf{5}$ in the manuscript. $J_{1}$ is the Bessel function of first kind.

From Figure S22, we found $\frac{I . q}{K C}=4.4 \times 10^{11} \mathrm{~g} \mathrm{~mol}^{-1} . \mathrm{cm}^{-1}$ in the q-region where $\mathrm{I}$ is $\mathrm{q}^{-1}$ dependent $\left(\mathrm{lq}=\mathrm{f}(\mathrm{q})\right.$ is constant), leading to $\mathrm{M}_{\mathrm{L}} \approx 1.4 \times 10^{4} \mathrm{~g} \cdot \mathrm{mol}^{-1} \cdot \mathrm{nm}^{-1}$ according to

\section{Equation S5.}

It was described by Lortie et al. ${ }^{9}$ that two consecutive bis(urea)s are separated by an intermolecular distance of $e=0.46 \mathrm{~nm}$ within the self-assembly. Assuming only one molecule in the cross-section and considering that the intermolecular distance is also e $=$ 
$0.46 \mathrm{~nm}$ in the co-assemblies of PEO-NDI- $\mathrm{U}_{2}$ and DAN- $\mathrm{U}_{2}$-PHEA in first approximation,

$\mathrm{M}_{\mathrm{L}}$ can be estimated with Equation S6:

$$
\mathrm{M}_{\mathrm{L}}=\frac{n_{D A N} \cdot M_{w}(\mathrm{DAN})+n_{N D I} \cdot M_{w}(\mathrm{NDI})}{\left(n_{D A N}+n_{N D I}\right) \times e}=\frac{x_{D A N} \cdot M_{w}(\mathrm{DAN})+x_{N D I} \cdot M_{w}(\mathrm{NDI})}{e} \text { (Equation S6) }
$$

where $n_{D A N}$ and $n_{N D /}$ respectively represent the number of PEO-NDI- $\mathrm{U}_{2}$ and DAN-U $\mathbf{U}_{2}$

PHEA molecules in the co-assembled nanocylinders, $x_{D A N}$ and $x_{N D /}$ their corresponding molar fractions and $M_{w}(D A N)=5700 \times 1.1 \mathrm{~g} \cdot \mathrm{mol}^{-1}$ and $M_{w}(N D I)=2500 \times 1.1 \mathrm{~g} \cdot \mathrm{mol}^{-1}$ their respective weight-average molecular weights.

For co-assemblies consisting of PEO-NDI- $\mathrm{U}_{2}$ and DAN- $\mathrm{U}_{2}$-PHEA in a 0.6:1 molar ratio with one molecule within the cross-section of the cylinders, $x_{D A N}=1 /(1+0.6)=0.38$ and $x_{N D I}=0.6 /(1+0.6)=0.62 ;$ leading to $\mathrm{M}_{\mathrm{L} 1}=1.1 \times 10^{4} \mathrm{~g} \cdot \mathrm{mol} \cdot \mathrm{nm}^{-1}$.

$M_{L 2}$ was moreover experimentally determined to be equal to $3.5 \times 10^{4} \mathrm{~g} \cdot \mathrm{mol} . \mathrm{nm}^{-1}$ for pure PEO-NDI- $U_{2}$ nanocylinders ${ }^{1}$. The average molecular weight per nanometer for a mixture containing 1.6 eq of PEO-NDI- $\mathrm{U}_{2} / \mathrm{DAN}-\mathrm{U}_{2}-\mathrm{PHEA}$ co-assemblies with a contrast $\mathrm{K}_{\mathrm{SANS} 1}=$ $2.19 \times 10^{-3} \mathrm{~mol} . \mathrm{cm}^{2} \cdot \mathrm{g}^{-2}$ and 0.4 eq. of pure PEO-NDI-U ${ }_{2}$ nanocylinders exhibiting a contrast 
$\mathrm{K}_{\mathrm{SANS} 2}=3.43 \times 10^{-3} \mathrm{~mol} \cdot \mathrm{cm}^{2} \cdot \mathrm{g}^{-2}$ could therefore be calculated according to Equation $\mathrm{S7}$ leading to $\mathrm{M}_{\mathrm{L}}($ average $)=1.5 \times 10^{4} \mathrm{~g} \cdot \mathrm{mol} \cdot \mathrm{nm}^{-1}$.

$\mathrm{M}_{\mathrm{L}}($ average $)=\frac{K_{\text {SANS1 } 1} C_{1} \cdot M_{L 1}+K_{S A N S 2} \cdot C_{2} \cdot M_{L 2}}{K_{\text {average }} \cdot C_{\text {total }}}$ (Equation S7)

Where $\mathrm{K}_{\text {average }}=2.33 \times 10^{-3} \mathrm{~mol} \cdot \mathrm{cm}^{2} \cdot \mathrm{g}^{-2}, \mathrm{C}_{1}, \mathrm{C}_{2}$ and $\mathrm{C}_{\text {total }}$ are the weight concentrations of respectively the PEO-NDI- $U_{2}(0.6$ eq. $)+\mathrm{DAN}_{-} \mathrm{U}_{2}-\mathrm{PHEA}$ ( 1 eq.) mixture, 0.4 eq. of PEONDI- $U_{2}$ and the PEO-NDI- $U_{2}$ (1 eq.) + DAN- $U_{2}$-PHEA (1 eq.) mixture $\left(C_{\text {total }}=C_{1}+C_{2}\right)$. The other parameters are defined above.

6.6. Characteristics of the pure DAN- $U_{2}-P H E A P E O-N D I-U_{2}$ co-assemblies in the premixed sample 
Since the scattering data of the pre-mixed solution contained the contribution of $40 \%$ pure PEO-NDI- $\mathrm{U}_{2}$ nanocylinders, the latter was subtracted in order to deduce the contribution of the sole Janus particles (Figure S23). The quality of the data was not as good as that for the initial solutions due to accumulation of experimental incertitude upon substraction. Still, comparison of these data with those of the pre-mixed solution suggest that the pure DAN- $\mathrm{U}_{2}$-PHEA/PEO-NDI- $\mathrm{U}_{2}$ co-assemblies consist of slightly shorter nanocylinders than those formed by PEO-NDI- $\mathrm{U}_{2}$ alone. They must also be more polydisperse considering the poor quality of a monodisperse fit. $\mathrm{M}_{\mathrm{L}} \approx 1.0 \times 10^{4} \mathrm{~g} \cdot \mathrm{mol}^{-1} \cdot \mathrm{nm}^{-}$ ${ }^{1}$ was found following the calculations explained in section 6.5. This value is in agreement with the theoretical value of $\mathrm{M}_{\mathrm{L} 1}=1.1 \times 10^{4} \mathrm{~g} \cdot \mathrm{mol} \cdot \mathrm{nm}^{-1}$ expected for co-assemblies consisting of PEO-NDI- $\mathrm{U}_{2}$ and DAN- $\mathrm{U}_{2}$-PHEA in a 0.6:1 molar ratio with one molecule within the cross-section of the cylinders. 


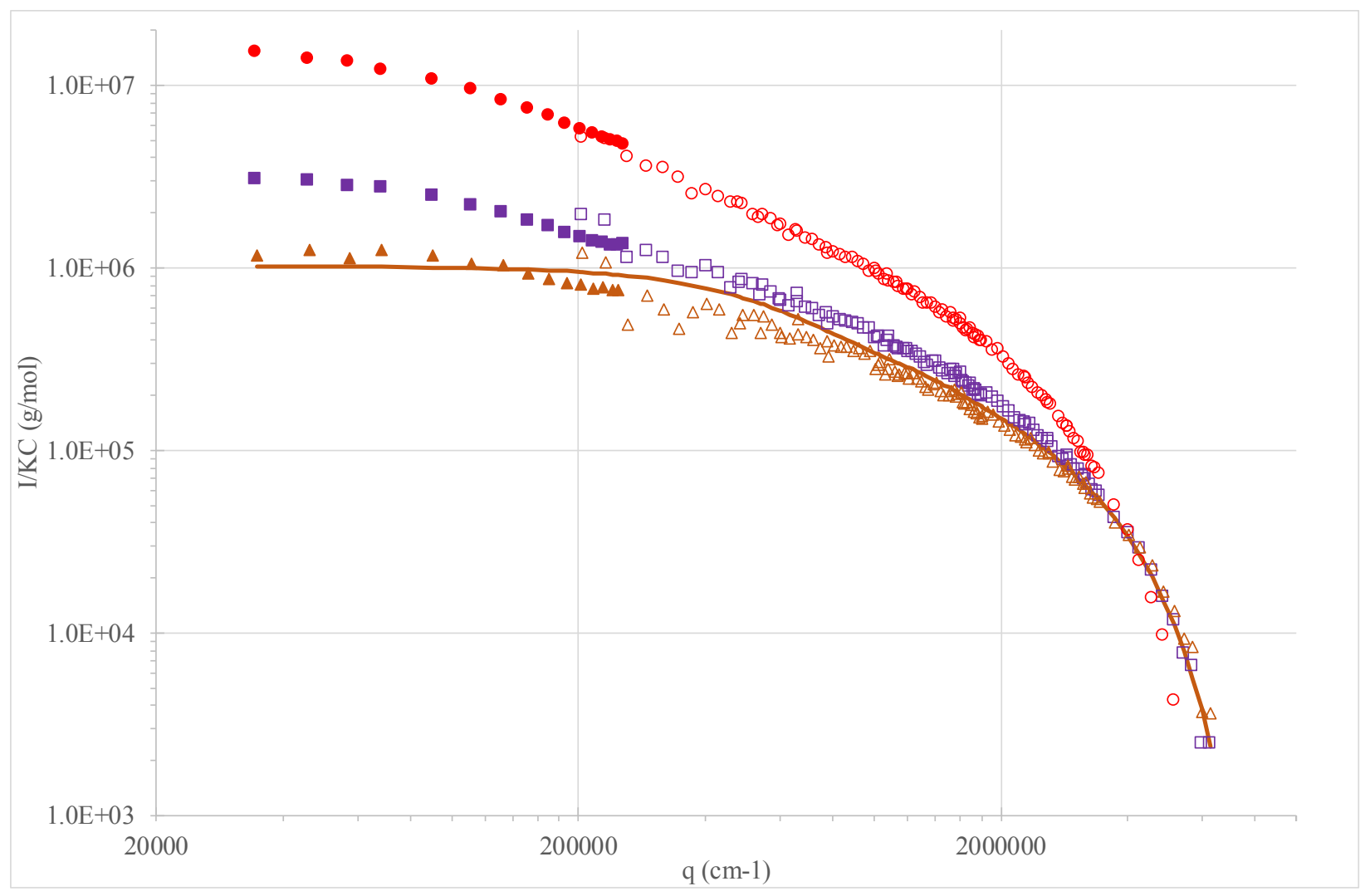

Figure S23. Evolution of the normalized scattering intensity $(\mathrm{I} / \mathrm{KC})$ as a function of the scattering wave vector (q) obtained by SLS (full symbols) and SANS (empty symbols) for: $(\square, \forall)$ the pre-mixed sample of PEO-NDI- $U_{2}(0.33 \mathrm{~g} / \mathrm{L})$ and DAN- $\mathrm{U}_{2}$-PHEA $(0.74 \mathrm{~g} / \mathrm{L})$ in $\mathrm{D}_{2} \mathrm{O} / \mathrm{DMSO}^{-} \mathrm{d}_{6}(99 / 1) ;(7, \triangle)$ the same sample from which the contribution of $40 \%$ of pure PEO-NDI- $U_{2}$ (corresponding to $0.13 \mathrm{~g} / \mathrm{L}$ ) was removed; $(\bullet,-)$ pure PEO-NDI- $\mathrm{U}_{2}$. The continuous line is the fit to a monodisperse cylinder model (with $M_{w}=1.2 \times 10^{6} \mathrm{~g} / \mathrm{mol}, L=80$ $\mathrm{nm}$ and $\left.\mathrm{R}_{\mathrm{c}}=5 \mathrm{~nm}\right)$. 


\section{Evidence of the role of hydrogen bonds: mixtures of PEO-NDI and DAN- $U_{2}-\mathrm{PHEA}$}

In order to highlight the importance of the complementarity of hydrogen bonding and charge transfer complex to obtain 1D Janus co-assemblies, DAN- $\mathrm{U}_{2}$-PHEA was mixed with PEO-NDI ${ }^{1}$ (analogue of PEO-NDI- $\mathrm{U}_{2}$ but lacking the bis(urea) group (Scheme S2) using the pre-mixing method. As mentioned above, DAN- $\mathrm{U}_{2}$-PHEA alone forms small spherical aggregates $\left(\mathrm{N}_{\mathrm{agg}} \approx 12, \mathrm{R}_{\mathrm{h}}=4 \mathrm{~nm}\right.$, see Table S2). PEO-NDI also forms small spherical aggregates $\left(\mathrm{N}_{\mathrm{agg}} \approx 10, \mathrm{R}_{\mathrm{h}}=5 \mathrm{~nm}\right)^{7}$ contrary to PEO-NDI-U $\mathrm{U}_{2}$. As previously, the mathematical sum of the raw scattered light intensity of individual DAN- $\mathrm{U}_{2}$-PHEA and PEO-NDI solutions was compared to that of the polymer mixture. Figure S24 shows that (1) within experimental uncertainty the light intensity scattered by the mixture is equal to the sum of the intensities scattered by individual solutions; (2) there is almost no angular dependency of the scattered light intensity and (3) the apparent molar mass in the premixed solution is very low. It can be concluded that pre-mixing DAN- $\mathrm{U}_{2}$-PHEA and PEONDI does not lead to the formation of long anisotropic co-assemblies. Very probably, both polymers do not co-assemble. This clearly proves that the combination of both the charge 
transfer complex and strong hydrogen bonds is necessary to form anisotropic 1D coassemblies.

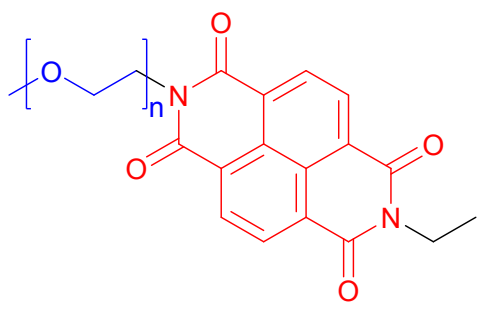

\section{PEO-NDI}

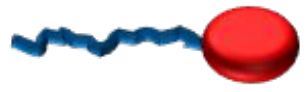

Scheme S2. Chemical structure PEO-NDI.

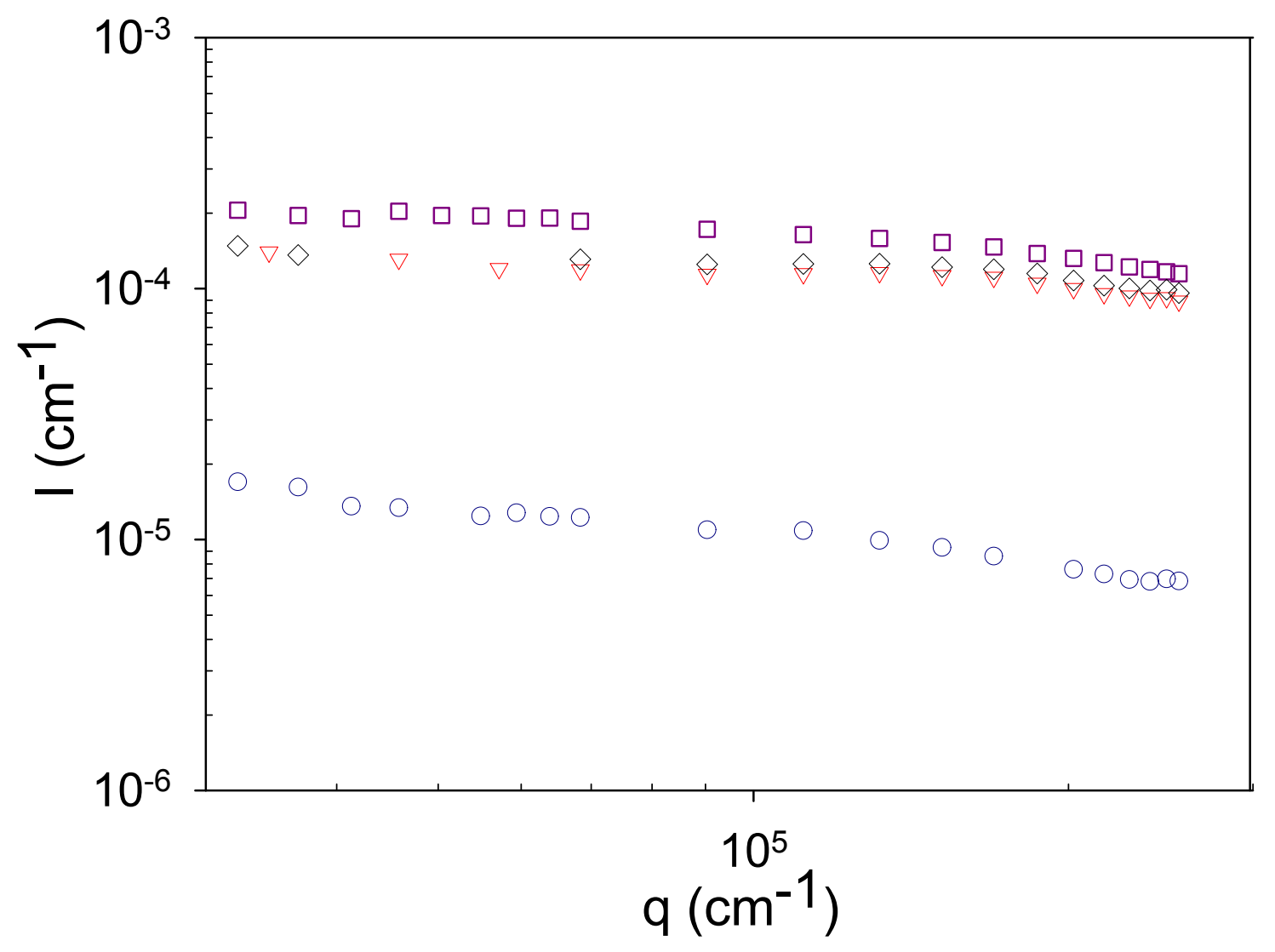


Figure S24. Wave vector (q) dependency of the raw scattered light intensity of DAN-U $\mathbf{U}_{2}$ PHEA at $C=10^{-4} \mathrm{~mol} / \mathrm{L}(\nabla), \mathrm{PEO}-\mathrm{NDI}$ at $\mathrm{C}=10^{-4} \mathrm{~mol} / \mathrm{L}(\bigcirc)$ and the equimolar pre-mixed solution of DAN-U U $_{2}$-PHEA and PEO-NDI $(\square)$ in water/DMSO $(9 / 1 \mathrm{v} / \mathrm{v})\left(\mathrm{C}_{\text {DAN-U2-PHEA }}=\right.$ $\left.\mathrm{C}_{\text {PEO-NDI-U2 }}=10^{-4} \mathrm{~mol} \cdot \mathrm{L}^{-1}\right)$. The diamonds $(\diamond)$ represent the mathematical sum of intensities scattered by DAN- $\mathrm{U}_{2}$-PHEA and PEO-NDI. 


\section{References}

1. Choisnet, T.; Canevet, D.; Sallé, M.; Nicol, E.; Niepceron, F.; Jestin, J.; Colombani,

O., Robust Supramolecular Nanocylinders of Naphthalene Diimide in Water. Chem.

Comm. 2019, 55(64), 9519-9522.

2. Nicol, E.; Derouineau, T.; Puaud, F.; Zaitsev, A., Synthesis of Double Hydrophilic

Poly(Ethylene Oxide)-b-Poly(2-Hydroxyethyl Acrylate) by Single-Electron Transfer-Living

Radical Polymerization. J. Polym. Sci. Part A: Polym. Chem. 2012, 50(18), 3885-3894.

3. Couchman, P. R., Prediction of Glass-Transition Temperature for Compatible

Blends Formed from Homopolymers of Arbitrary Degree of Polymerization.

Compositional Variation of Glass-Transition Temperatures. 5. Macromolecules 1980, 13

(5), 1272-1276.

4. Fox, T. G., Influence of Diluent and of Copolymer Composition on the Glass

Temperature of a Polymer System. Bull. Am. Phys. Soc. 1956, 1, 123. 
5. Charbonneau, C.; Lima, M. M. D.; Chassenieux, C.; Colombani, O.; Nicolai, T.,

Structure of $\mathrm{pH}$ Sensitive Self-Assembled Amphiphilic Di- and Triblock

Copolyelectrolytes: Micelles, Aggregates and Transient Networks. Phys. Chem. Chem.

Phys. 2013, 15(11), 3955-3964.

6. Chassenieux, C.; Nicolai, T.; Durand, D., Association of Hydrophobically End-

Capped Poly(Ethylene Oxide). Macromolecules 1997, 30 (17), 4952-4958.

7. Han, S.; Nicol, E.; Niepceron, F.; Colombani, O.; Pensec, S.; Bouteiller, L., Oligo-

Urea with No Alkylene Unit Self-Assembles into Rod-Like Objects in Water. Macromol.

Rapid Commun. 2019, 40, 1800698.

8. Lefay, C.; Charleux, B.; Save, M.; Chassenieux, C.; Guerret, O.; Magnet, S. p., Amphiphilic Gradient Poly(Styrene-co-Acrylic Acid) Copolymer Prepared via Nitroxide-

Mediated Solution Polymerization. Synthesis, Characterization in Aqueous Solution and Evaluation as Emulsion Polymerization Stabilizer. Polymer 2006, 47 (6), 1935-1945. 
9. Lortie, F.; Boileau, S.; Bouteiller, L.; Chassenieux, C.; Demé, B.; Ducouret, G.; Jalabert, M.; Lauprêtre, F.; Terech, P., Structural and Rheological Study of a Bis-Urea Based Reversible Polymer in an Apolar Solvent. Langmuir 2002, 18 (19), 7218-7222.

10. Terech, P.; Coutin, A., Structure of a Transient Network Made up of Entangled Monomolecular Organometallic Wires in Organic Liquids. Effects of an Endcapping Molecule. Langmuir 1999, 15(17), 5513-5525. 